\title{
Coastal Boundary Layer Characteristics of Wind, Turbulence, and Surface Roughness Parameter over the Thumba Equatorial Rocket Launching Station, India
}

\author{
K. V. S. Namboodiri, ${ }^{1}$ Dileep Puthillam Krishnan, ${ }^{1}$ Rahul Karunakaran Nileshwar, ${ }^{1}$ \\ Koshy Mammen, ${ }^{1}$ and Nadimpally Kiran kumar ${ }^{2}$ \\ ${ }^{1}$ Meteorology Facility, Thumba Equatorial Rocket Launching Station (TERLS), Vikram Sarabhai Space Centre (VSSC), \\ Indian Space Research Organisation, Thiruvananthapuram 695 022, India \\ ${ }^{2}$ Space Physics Laboratory, Vikram Sarabhai Space Centre (VSSC), Indian Space Research Organization, \\ Thiruvananthapuram 695 022, India
}

Correspondence should be addressed to K. V. S. Namboodiri; sambhukv@yahoo.com

Received 18 October 2013; Revised 25 February 2014; Accepted 9 March 2014; Published 19 June 2014

Academic Editor: Elena Paoletti

Copyright (C) 2014 K. V. S. Namboodiri et al. This is an open access article distributed under the Creative Commons Attribution License, which permits unrestricted use, distribution, and reproduction in any medium, provided the original work is properly cited.

\begin{abstract}
The study discusses the features of wind, turbulence, and surface roughness parameter over the coastal boundary layer of the Peninsular Indian Station, Thumba Equatorial Rocket Launching Station (TERLS). Every 5 min measurements from an ultrasonic anemometer at $3.3 \mathrm{~m}$ agl from May 2007 to December 2012 are used for this work. Symmetries in mesoscale turbulence, stress off-wind angle computations, structure of scalar wind, resultant wind direction, momentum flux $(M)$, Obukhov length $(L)$, frictional velocity $\left(u_{*}\right)$, w-component, turbulent heat flux $(H)$, drag coefficient $\left(C_{D}\right)$, turbulent intensities, standard deviation of wind directions $\left(\sigma_{\theta}\right)$, wind steadiness factor- $\sigma_{\theta}$ relationship, bivariate normal distribution (BND) wind model, surface roughness parameter $\left(z_{0}\right), z_{0}$ and wind direction $(\theta)$ relationship, and variation of $z_{0}$ with the Indian South West monsoon activity are discussed.
\end{abstract}

\section{Introduction}

The lowest layers of the earth's atmosphere based on wind variation with height are categorized into different layers such as (1) laminar sublayer, (2) Prandtl layer, and (3) Ekman spiral layer. (1) and (2) are together called surface boundary layer (SBL) or surface layer (SL) or the tower layer or constant flux layer. SBL studies can find applications in wind power meteorology, aviation meteorology, aerospace meteorology, structural loading, air pollution, flow modeling, biometeorology, and weather forecast models. In the SBL, more specifically in Prandtl layer, the eddy stress (due to turbulence) is an order of magnitude larger than the horizontal pressure gradient force. Several approximations are available regarding SBL [1-3] about the height, vertical stress, heat flux, wind direction, turbulent diffusion, and insignificance of Coriolis effect. In a diabatic (nonadiabatic) atmosphere, the thermodynamic change of the state of the system is one in which there is transfer of heat across the boundaries of the system [4]. A general formula for the diabatic (nonadiabatic) wind profile in the SBL can be derived $[3,5]$ which provides the height above the earth's surface where the mean wind speed $(\bar{u})$ vanishes before the surface is called as the surface roughness parameter $\left(z_{0}\right)$ :

$$
z_{0}=\frac{z}{\exp \left(\left(\bar{u} k / u_{*}\right)+\psi(z / L)\right)},
$$

where $z$ is the wind measuring level, $\psi$ is the universal function of height $z$ relative to the Monin-Obukhov (MO) similarity theory [6], $u_{*}$ is the frictional velocity, $k$ is the von Karman constant $(\approx 0.4)$, and $L$ is the Obukhov length. To determine the surface roughness parameter, stability corrected method proposed by Paulson [7] is used. The stability corrected Businger [5] method uses constants 4.7 and 
15 instead of 5 and 16 which are used in Paulson [7]. Businger method can be seen in Rao et al. [8].

If $(z / L)>0$ (stable),

$$
\psi\left(\frac{z}{L}\right)=-5 \frac{z}{L}
$$

and when $z / L<0$ (unstable),

$$
\psi\left(\frac{z}{L}\right)=2 \log \left[\frac{(1+x)}{2}\right]+\log \left[\frac{\left(1+x^{2}\right)}{2}\right]-2 \tan ^{-1}(x)+\frac{\pi}{2},
$$

where $x \equiv[(1-16(z / L))]^{1 / 4}$. If $z / L=0$, the $z_{0}$ value pertained to logarithmic wind profile in neutral case can be obtained as

$$
z_{0}=\frac{z}{\exp \left(\bar{u} k / u_{*}\right)}
$$

The relation of $z_{0}$ to various terrain types is extensively studied by Nappo [9], Smedman-Hogstrom and Hogstrom [10], Hicks et al. [11], Kondo and Yamazawa [12], Thompson [13], and Garratt [14] and occurrence of imaginary and small $z_{0}$ values was reported by Panofsky and Peterson [15] over a narrow peninsula surrounded by bays of varying width. The $z_{0}$ values may vary with the heights of wind measurements as profiles from tower will sense only local terrain irregularities of small horizontal size and also at the low level the roughness length is representative of the locally smooth surface crops $[16,17]$. From a limited period data, Ramachandran et al. [18] have studied the variability of $z_{0}$ for Indian coastal station, Thumba, and reported that the $z_{0}$ values are low during the Indian South West monsoon (SW monsoon) season compared to other months. For the same station, Gupta et al. [19] have shown that $z_{0}$ is maximum when onshore flow is perpendicular to the coast. Namboodiri [20] has documented direct proportionality among $z_{0}$ and exponent in wind power law and diurnal variation of $z_{0}$ and its dependence with wind direction.

Surface roughness parameter values have application in oil sleek sedimentation and evaporation modeling. Studies on the influence of marine boundary layer on land boundary layer are very limited. Properties of marine boundary layer were studied [26, 27]. Lange et al. [28] suggested that MO similarity theory cannot be applied to the coastal marine boundary layer under stable and warm advections. Momentum and sensible heat exchange in an Arctic Fjord was carried out by Kilpelainen and Sjoblom [29] which has proved the application of MO similarity theory under "nonideal" conditions. Marine boundary layer changes are due to behaviors in wind speed, sea water surface tension, stress by young developing and decaying waves, changing wind direction, water depth, wave breaking, wave strength, fetch, and shoreline processes.

Sonic anemometer measures wind data at high frequency rate and eddy-correlation method facilitates estimation of turbulence parameters. From the high frequency $(10 \mathrm{~Hz}$.) $x$, $y$, and $z$ wind components, the total stress $\tau$, and thereby drag coefficient $\left(C_{D}\right)$, and stress off-wind angle $(\alpha)$ can be computed as

$$
\begin{gathered}
\tau=\rho u_{*}^{2}, \\
C_{D}=\left\{\frac{k}{\left[\ln \left(z / z_{0}\right)-\psi(z / l)\right]}\right\}^{2}, \\
\alpha=\tan ^{-1}\left(\frac{\left\langle v^{\prime} w^{\prime}\right\rangle}{\left\langle u^{\prime} w^{\prime}\right\rangle}\right),
\end{gathered}
$$

where $\rho$ is the air density, $u_{*}=\left[\left\langle u^{\prime} w^{\prime}\right\rangle^{2}+\left\langle v^{\prime} w^{\prime}\right\rangle^{2}\right]^{1 / 4}$, and the vertical transport of horizontal momentum and $\left\langle u^{\prime} w^{\prime}\right\rangle$, $\left\langle v^{\prime} w^{\prime}\right\rangle$ are the components of the kinematic momentum flux in the along wind and cross wind directions, respectively. A positive (negative) $\alpha$ corresponds to the stress vector orientation to right (left) of the wind direction; that is, the stress vector is shifted clockwise (anticlockwise) from the wind direction. Using eddy-correlation method $L$, vertical momentum flux (negative $\tau$ ) and turbulent heat flux $(H)$ are computed:

$$
\begin{gathered}
L=\frac{-u_{*}^{3} T}{g k\left\langle w^{\prime} T^{\prime}\right\rangle}, \\
H=\rho C_{p}\left\langle w^{\prime} T^{\prime}\right\rangle,
\end{gathered}
$$

where $g$ is the acceleration due to gravity, $C_{p}$ is the specific heat of dry air at constant pressure, and $\left\langle w^{\prime} T^{\prime}\right\rangle$ is the kinematic temperature flux $\left(T^{\prime}\right.$ is the perturbations in sonic temperature, $T$ ).

This study presents the features of wind, turbulence, and $z_{0}$ over the peninsular coastal boundary layer over the Thumba Equatorial Rocket Launching Station, TERLS, $\left(8^{\circ} 32^{\prime} \mathrm{N} / 76^{\circ} 52^{\prime} \mathrm{E}, 6 \mathrm{~m}\right.$ above $\left.\mathrm{msl}\right)$, a place in Thiruvananthapuram, the capital city of the Kerala state of India.

\section{Experimental Site and Data Base}

Figure 1 shows the locations of TERLS in the west coast and Sriharikota in the east coast situated in the south Peninsular India. Sriharikota $\left(13^{\circ} 42^{\prime} \mathrm{N} / 80^{\circ} 12^{\prime} \mathrm{E}\right)$ is marked for the sake of an analysis mentioned about the local wind direction variability during the SW monsoon over both stations.

An Ultra Sonic Anemometer (USA1, M/s Metek, Germany) is installed in TERLS at a height of $3.3 \mathrm{~m}$ above the ground level. In the near vicinity, the soil is sandy with sparsely grown very short grass vegetation. Cashew plantations of less than $8 \mathrm{~m}$ in height are about $50 \mathrm{~m}$ far in the NNW to ENE sectors. Wide open sandy yard in the ENE to SSE sector is about $10000 \mathrm{~m}^{2}$ in area. A height level of $3.3 \mathrm{~m}$ represents statistics of surface wind and turbulence for our applications of interest. The sonic anemometer is located at about $140 \mathrm{~m}$ from the Arabian seashore line (oriented $145^{\circ}-325^{\circ}$ azimuth). This provides a unique opportunity to capture coastal boundary layer wind modifications due to the marine SBL. Onshore winds arrive through very sparingly planted medium size coconut trees of less than 


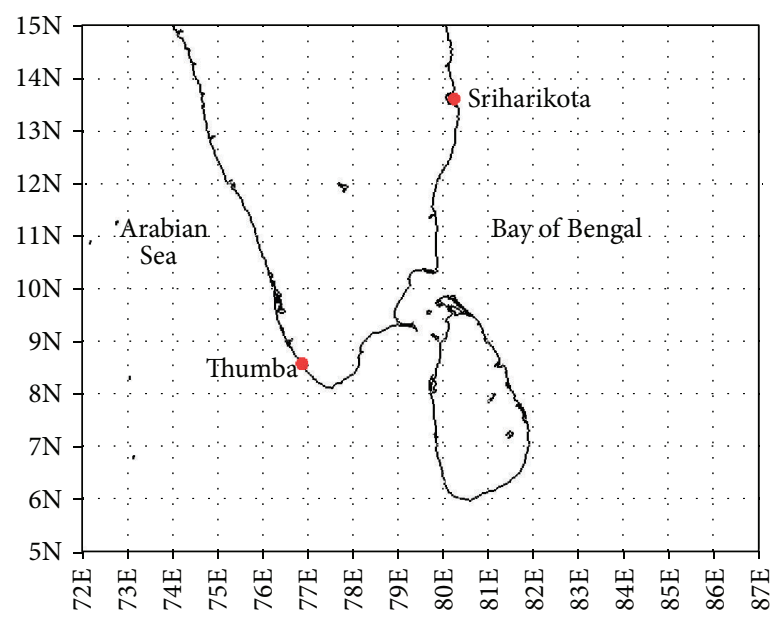

Figure 1: Peninsular India showing the locations of Thumba and Sriharikota.

$8 \mathrm{~m}$ within a distance of $50 \mathrm{~m}$ to $140 \mathrm{~m}$. Meteorology facility, TERLS, has the heaviest responsibility in supporting regular sounding rocket launches from the launch pad located on the seashore. Wind climatology, SBL wind variability due to mesosynoptic features, role of turbulent parameters in environmental assessments, namely, corrosion, evaporation, coastal sedimentation processes are highly significant for the engineering demands at TERLS and thereby this project is commissioned. Round the clock 5-minute observations of wind and turbulent parameters (based on MO similarity theory) are obtained by using $10 \mathrm{~Hz}$ data. The data from May 2007 to December 2012 (more than 5 years) is used for time section isopleth analyses to depict mean wind and turbulent parameters. Stress off-wind angle calculations are made to know the influence of marine boundary layer. The variability of $z_{0}$ in relation to the SW monsoon season has been investigated.

\section{Data Validation through Symmetries and Distributions in Mesoscale Turbulence}

Through dimensional analysis Brutsaert [30] identified that the normalized turbulence or statistics-variances, covariances, and gradients are universal functions of $z / L$. Also the relation between turbulent statistics and $z / L$ is to be empirically determined. Extensive data validation processes are made through universal symmetries and scatter distribution diagrams of mesoscale turbulence $[3,25,31]$. For the same station Ramachandran et al. [18] and Kunhikrishnan [32] have studied surface layer variables expressed in universal form by means of scaling parameters. Krishnan and Kunhikrishnan [22] have reported relations among normalized standard deviations of variables to $z / L$ within the tropic of cancer. Ramana et al. [24] have documented the same outside the tropic of cancer. In the present study $z / L$ values are categorized into stable-unstable cases for onshore and offshore winds. Kaimal and Finnigan [33] have discussed the significance of well-defined spectral properties in boundary layer characterization studies. Prakash et al. [34] have shown distinct spectral features for the mesoscale circulations over this coastal station. Due to this finding, all the obtained data points have been taken in the analyses on the universal symmetry and distributions of turbulence. Onshore wind (from $145^{\circ}$ to $325^{\circ}$ ) and offshore wind (from $325^{\circ}$ to $145^{\circ}$ ) are separately considered while deriving the symmetries. +ve and -ve $L$ values correspond to stable and unstable SBL, respectively.

Figure 2 provides distribution of $u_{*}$ Vs $1 / L$ for the months January and July represent winter $(D, J)$ and SW monsoon ( $J$, $J, A, S)$, respectively, in India. +ve and -ve $u_{*}$ values adopted in discussions are reasoned as follows. Biltoft [35] reported that frictional velocity and $L$ cannot be properly defined if momentum flux is positive, even though these equations will produce what appears to be a mathematically correct result. As a convention, during the incidence of positive momentum flux, the $u_{*}$ values are reported as negative values [36]. Mathematically positive momentum flux has to generate a negative Reynolds stress term and hence negative $u_{*}$ and $C_{D}$ values. Convention adopted in $u_{*}$ during positive momentum flux is an embedded feature in the onboard computation of the instrument. One can expect either a positive or negative slope in the logarithmic wind profile with respect to wind speed increases or decreases, respectively, with height. Accordingly, more precise interpretation may be conventionally explained as +ve $u_{*} /-$ ve $u_{*}$ for +vely/-vely slopped logarithmic wind profiles (+ve/-ve momentum flux corresponds to -vely/+vely slopped logarithmic wind profile by convention). $u_{*}$ peaks at $1 / L \rightarrow 0$ ( $\tau$ also peaks up due to (5)), for both onshore and offshore wind cases. $u_{*}$ becomes small for both negative and positive increases of $1 / L$ values. Small $u_{*}$ values against high negative and positive $1 / L$ values are due to dominant convection (highly unstable) and severely reduced mechanical turbulence (highly stable) due to temperature stratification, respectively. Medium values of both +ve and -ve values that fall in between $1 / L \rightarrow 0$ and $<$ high $\pm 1 / L$ values contribute to mechanical turbulence slightly damped by temperature stratification (weakly stable) and dominant mechanical (inertial) turbulence (weakly unstable). Peak values of $u_{*}$ when $1 / L \rightarrow 0$ are due to neutral regime characterized by purely mechanical turbulence. Even with the momentum flux becomes positive (thereby negative $u_{*}$ ), the peaking of $u_{*}$ when $1 / L \rightarrow 0$ is observed irrespective of onshore or offshore wind. A universal symmetry relation cannot be established between $u_{*}$ and $1 / L$.

To see the contribution of $w$ component in $u_{*}, u_{*}$ values are plotted against standard deviation of $w$-components $\left(\sigma_{w}\right)$ as in Figure 3. Steep linear slopes are observed during offshore and onshore events, which shows increase in $u_{*}$ values with increase in standard deviation of $w$ components. The near constancy in slopes with value about 1.3 provides a typical neutral $u_{*}$ value of the order of about $0.7 \mathrm{~ms}^{-1}$ and the same may be noticed from Figure 2 .

In contrast to the standard deviation of vertical velocity, those of the horizontal components over uniform terrain do not vary with height in the surface layer, not even in unstable air, but depend strongly on temperature stratification 


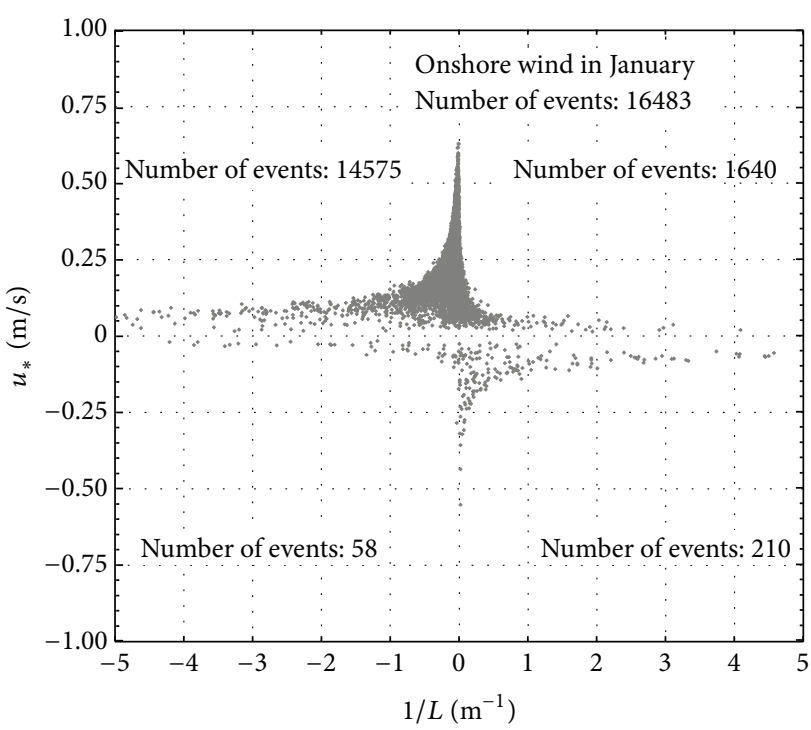

(a)

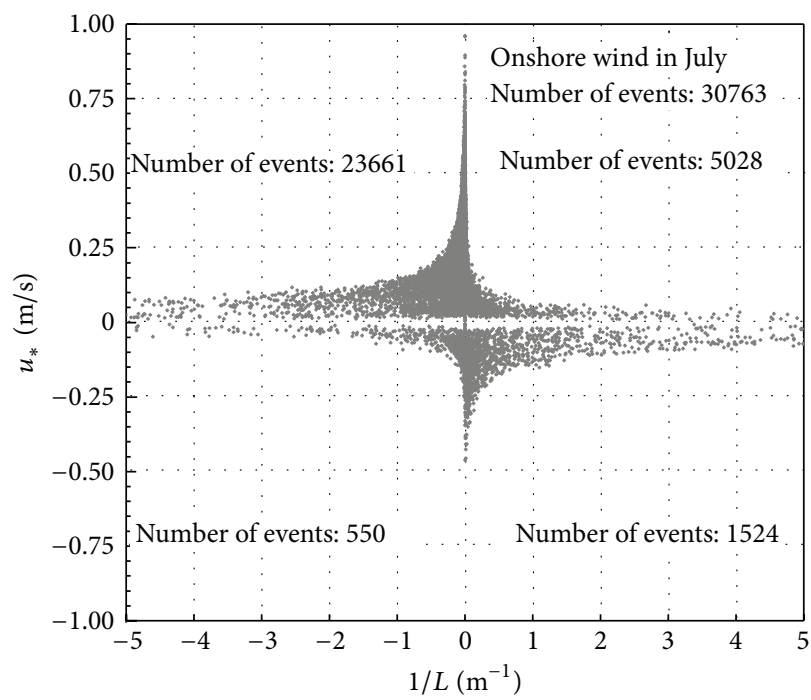

(c)

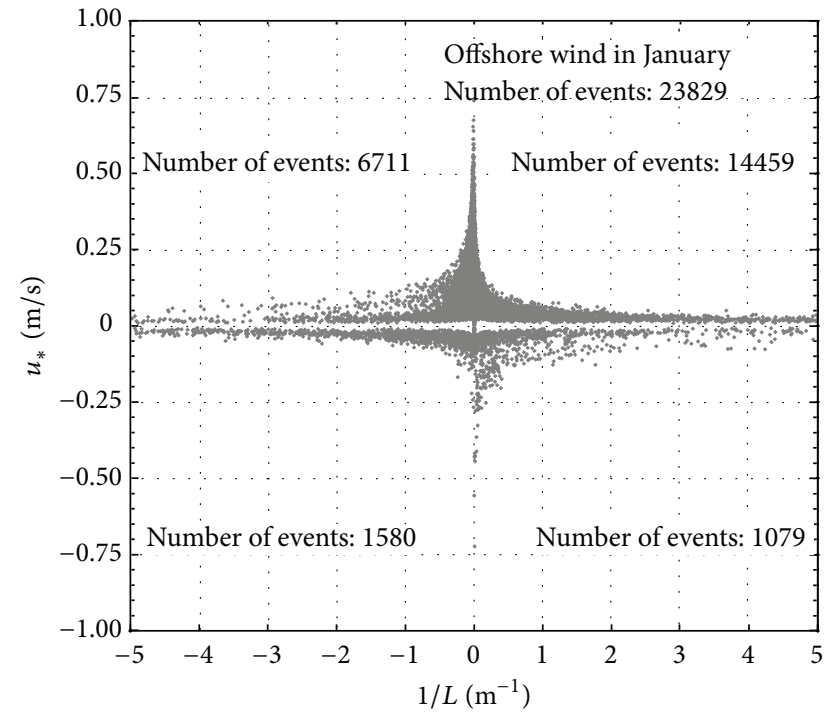

(b)

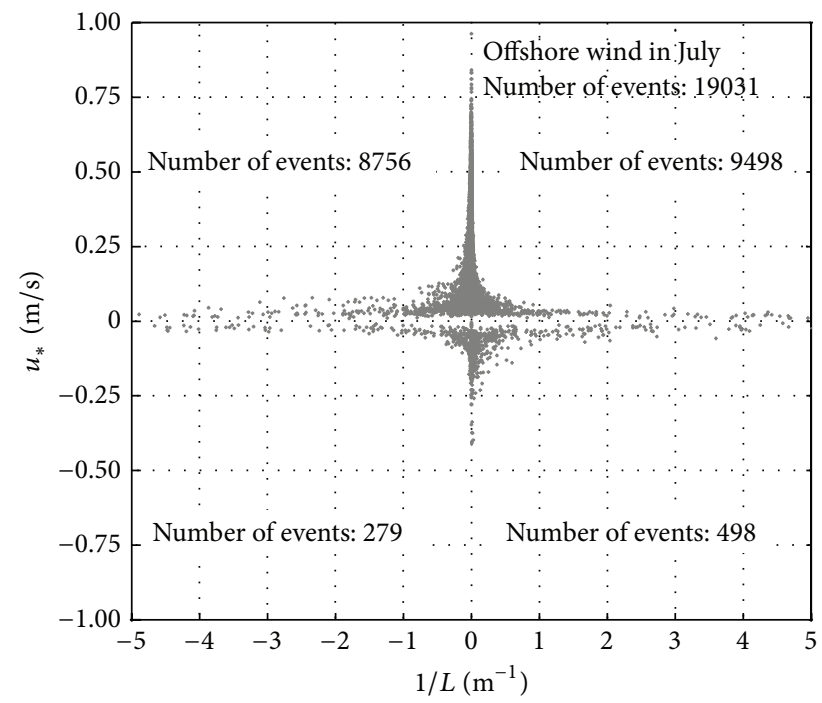

(d)

FIgURE 2: Distribution between $u_{*}$ and $1 / L$ for January and July.

$[3,37,38]$. With this background knowledge, we have studied the dependence of variances of lateral $(p)$, longitudinal $(q)$, and vertical $(r$ or $w)$ components normalized by $u_{*}$ and $z / L$. Studies among variances of wind components to $z / L$ are available mostly outside the tropics $[39,40]$. In the present study, investigators could obtain power curves relations of the form $\sigma / u_{*}=a+b(z / L)^{c}$ among variances of $p, q$, and $r$ components normalized by $u_{*}$ and $z / L$ for both $z / L>0$ and $z / L<0$ similar to what Pahlow et al. [25] studied for $z / L>0$. On the $x$-axis $\pm z / L$ values are depicted from 0 to 300 . The power curve relations result in the dependence of $(p, q, r)$ variances on $z / L$ by considering data points of more than 15000 samples individually for the stable and unstable regime of onshore and offshore cases (Figures 4(a)$4(c))$. Towards the origin of the fitted curves among standard deviations of $(p, q$, and $r)$ and $z / L$, magnitude of $\pm z / L$ values decreases to extremely low values. Scattering of variances with respect to $z / L$ is at its minimum level from -10 to 10 and is characterized by maximum points of occurrence. Variances are not showing much $z / L$ dependence over this regime of weakly stable or weakly unstable conditions. Abrupt enhancement in $\sigma_{p} / u_{*}, \sigma_{q} / u_{*}$, and $\sigma_{r} / u_{*}$ can be seen from $z / L$ values $<-10$ and $>10$ in association with highly unstable or highly stable conditions, respectively. A 1/3 power relation for unstable regime and power as unity for stable regime exists between $\sigma_{r} / u_{*}$ and $z / L$. No relation among horizontal fluctuations (lateral and longitudinal) with $z / L$ due to the control of convective motions over horizontal velocity variances attributed to mixed layer scaling down to the surface was suggested by several investigators [21, $22,24,32$ ]. Panofsky et al. [21] specifically mentioned only an approximate agreement of $1 / 3$ power relation among 


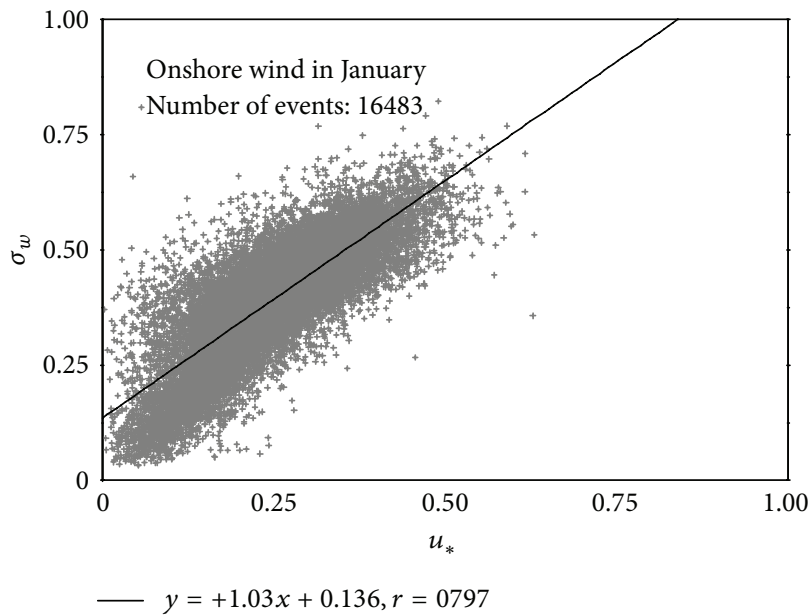

(a)

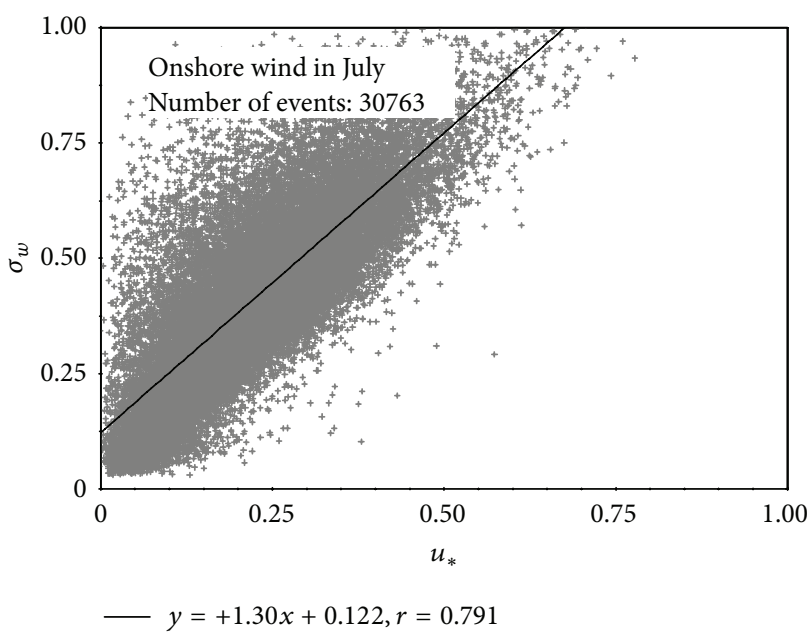

(c)

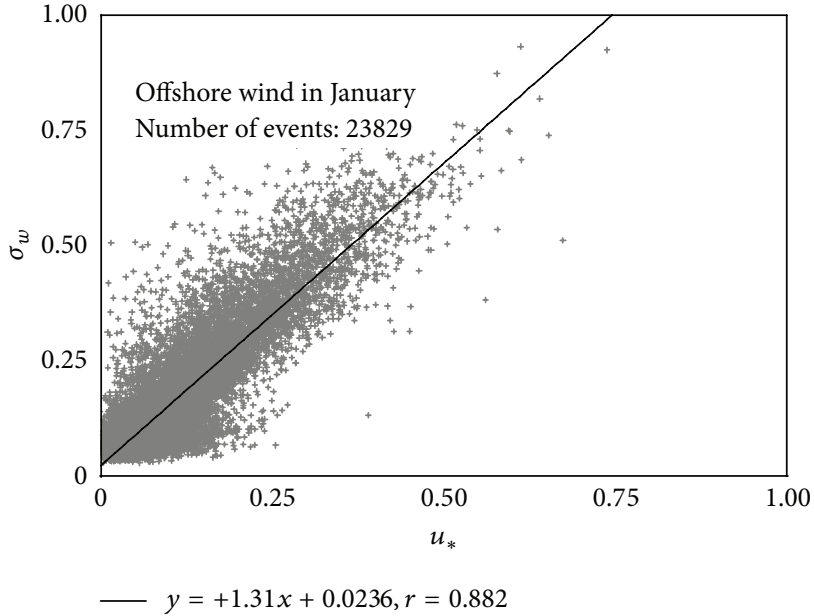

(b)

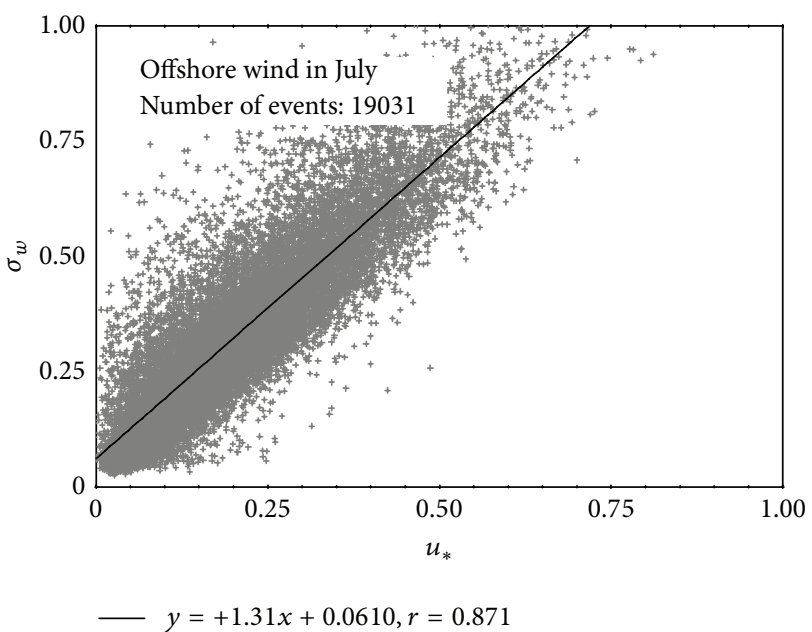

(d)

FIGURE 3: Relation between frictional velocity and standard deviation of $w$-component.

variances of wind components to $z / L<0$. Table 1 provides various relations among normalized standard deviation of vertical component $\left(\sigma_{r} / u_{*}\right.$ or $\left.\sigma_{w} / u_{*}\right)$ to $z / L$. The investigators could obtain power curve relations among $(p, q, r)$ variances and $z / L$ with high correlation coefficient $(r)$ values, for both stable and unstable flow regimes.

Stray points are observed in the negative portion of the standard deviation normalized by $u_{*}$. Interestingly these negative ordinate portions also have shown similar power relations. Approaching the neutral regime, negative $u_{*}$ values are drastically reduced due to positively slopped classical neutral logarithmic wind profile approximation. In this part of analysis near neutral approximations are obtained (through nonoccurrence of negative $u_{*}$ ) specifically within the region of $z / L$ from -0.03 to 0.02 . Rieder et al. [41] have mentioned $z / L$ between -0.01 and 0.01 as the neutral regime and Ramana et al. [24] quantified it as -0.1 to 0.1. Curve fittings from other investigators for the unstable and stable regimes are also incorporated in Figure 4.
Figure 5 represents the relation between $z / L$ and sonic temperature normalized by characteristic temperature $\left(T_{*}\right)$. For comparison power curve fittings following Pahlow et al. [25] are depicted in the figure.

Figure 6 shows the scatter plot of wind directions against $z / L$ for offshore and onshore wind regimes separated by straight lines. +ve $z / L$ values are markedly lacking in the onshore wind regime, but both +ve and -ve $z / L$ contributions are seen in the offshore wind regime. This concludes that onshore SBL wind profiles are of mostly unstable nature, whereas offshore wind profiles can belong to either stable or unstable type.

As the sonic anemometer is very close to the shoreline, a detailed examination on stress off-wind angle $(\alpha)(7)$ is carried out for $\alpha$ values, which vary from $-180^{\circ}$ to $180^{\circ}$. Similar studies can be seen elsewhere [27, 41-43]. These analyses can find application in estimating the direction of wind driven sea waves near to the coast over this region of the Arabian sea. Inverse relationship is seen between stress off-wind angle and wind speed (Figure 7). 


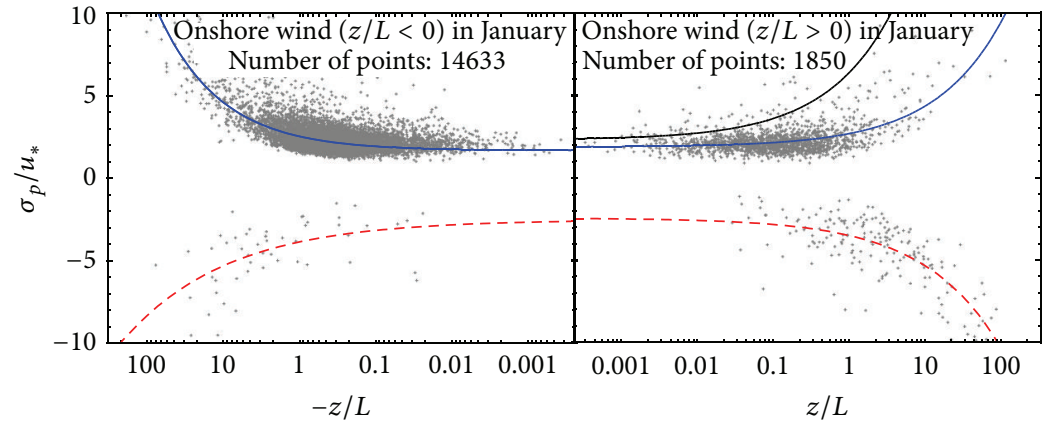

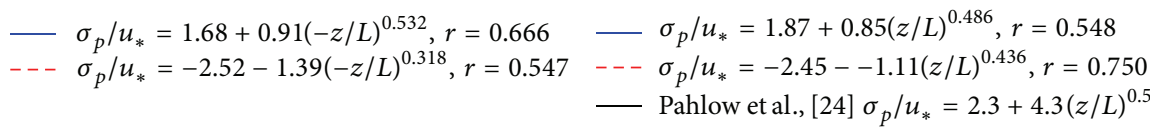

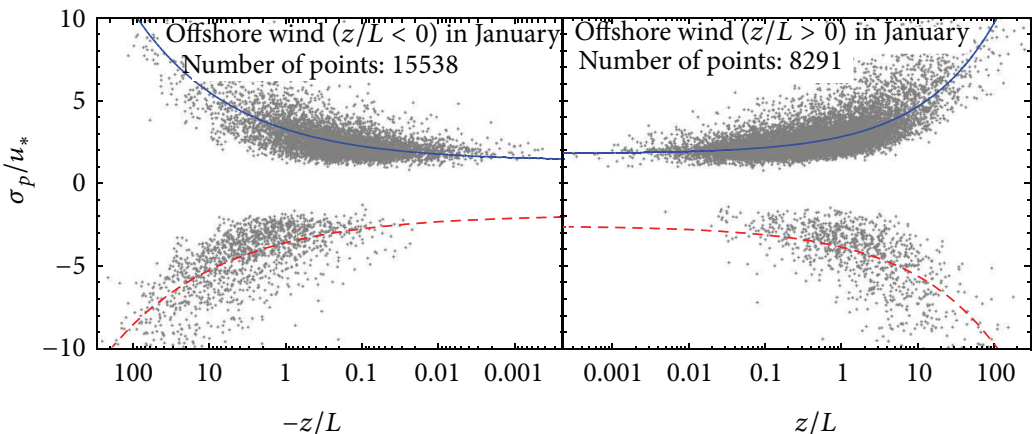

$-\sigma_{p} / u_{*}=1.68+0.91(-z / L)^{0.532}, r=0.729-\sigma_{p} / u_{*}=1.78+1.03(z / L)^{0.442}, r=0.727$
$--\sigma_{p} / u_{*}=1.90-1.69(-z / L)^{0.297}, r=0.682--\sigma_{p} / u_{*}=-2.75-1.29(z / L)^{0.371}, r=0.664$

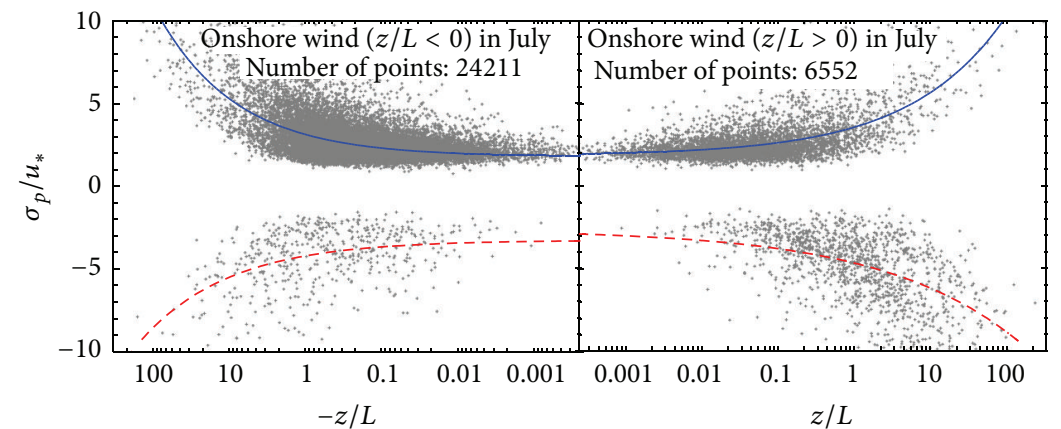

$\begin{aligned} &-\sigma_{p} / u_{*}=1.80+1.40(-z / L)^{0.418}, r=0.587-\sigma_{p} / u_{*}=1.84+1.77(z / L)^{0.347}, r=0.628 \\ &---\sigma_{p} / u_{*}=-3.26-0.99(-z / L)^{0.373}, r=0.434--\sigma_{p} / u_{*}=-2.66-2.07(z / L)^{0.243}, r=0.547\end{aligned}$

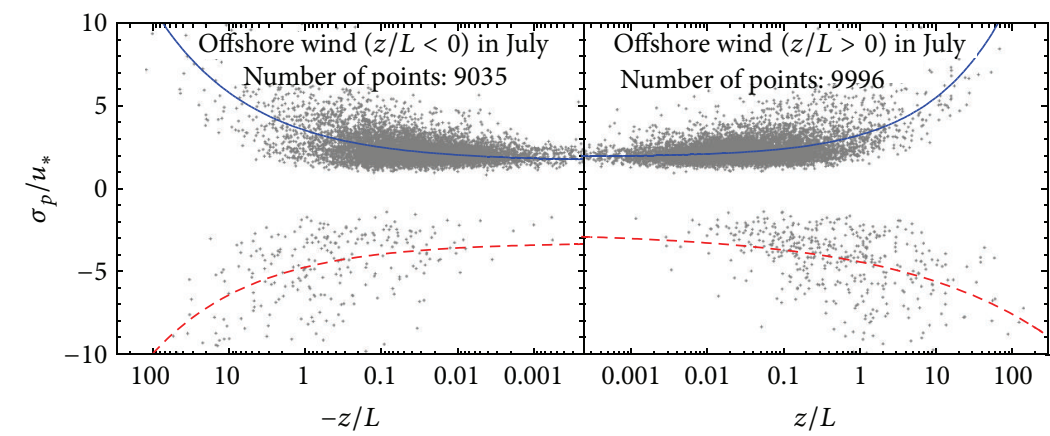

$-\sigma_{p} / u_{*}=1.66+1.85(-z / L)^{0.349}, r=0.552-\sigma_{p} / u_{*}=1.91+1.33(z / L)^{0.432}, r=0.522$
$--\sigma_{p} / u_{*}=-3.26-1.49(-z / L)^{0.326}, r=0.488--\sigma_{p} / u_{*}=-2.63-1.80(z / L)^{0.219}, r=0.452$

(a)

Figure 4: Continued. 

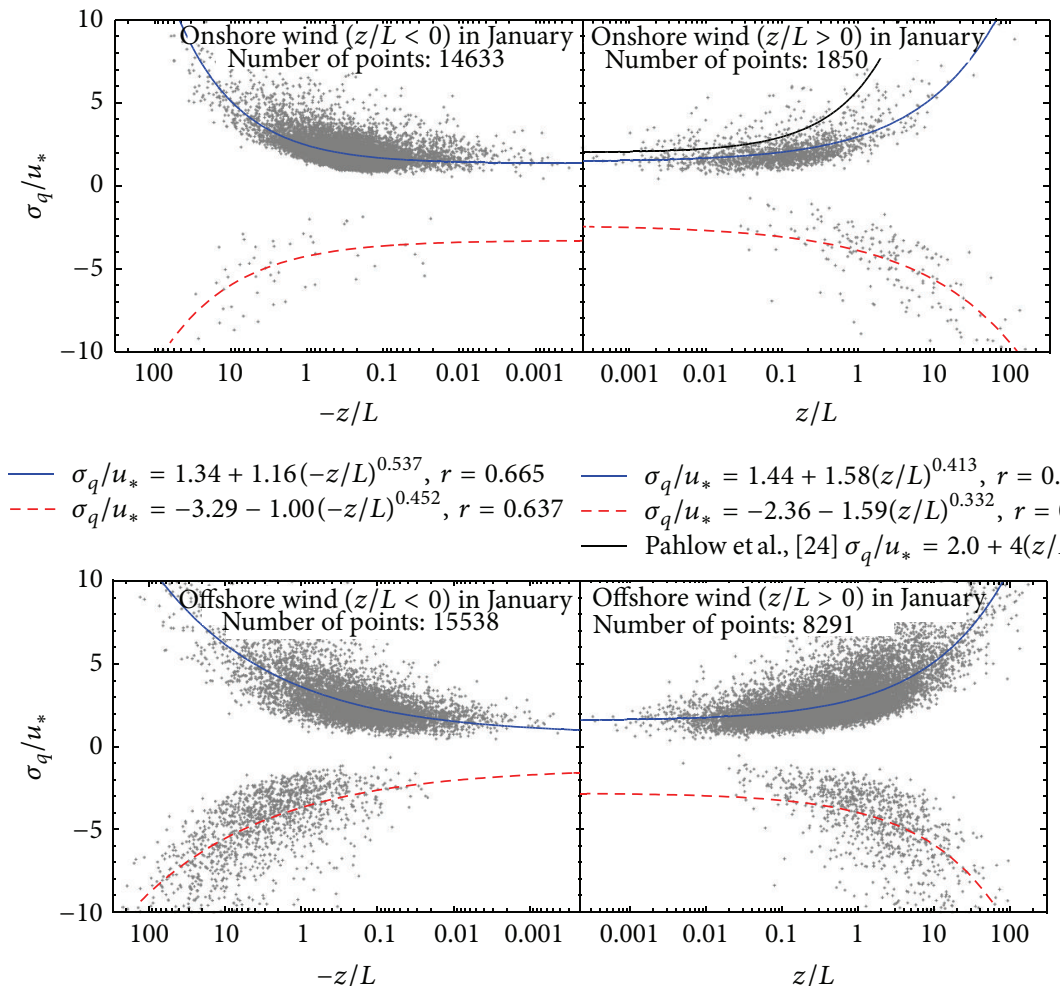

$-\sigma_{q} / u_{*}=0.72+2.90(-z / L)^{0.275}, r=0.727-\sigma_{q} / u_{*}=1.56+1.38(z / L)^{0.414}, r=0.686$
$---\sigma_{q} / u_{*}=-1.28-2.40(-z / L)^{0.250}, r=0.653--\sigma_{q} / u_{*}=-2.80-1.19(-z / L)^{0.422}, r=0.616$

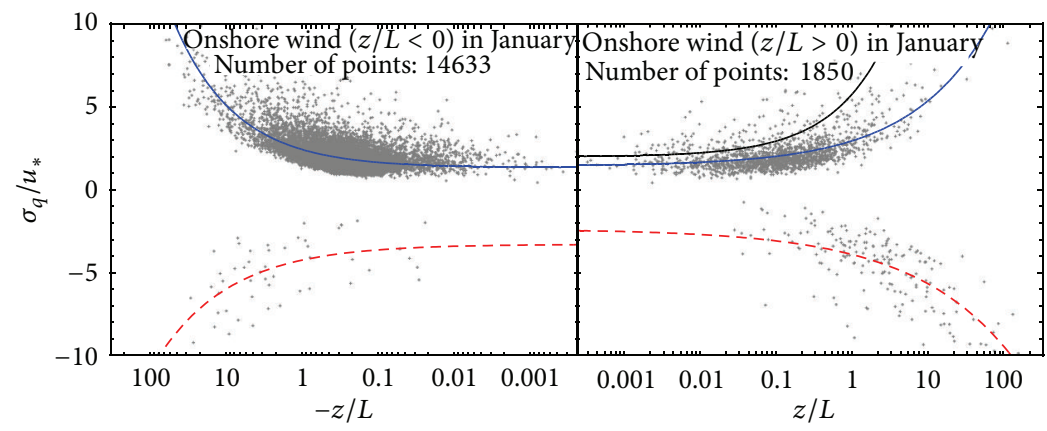

$$
\begin{aligned}
-\sigma_{q} / u_{*}=1.34+1.16(-z / L)^{0.537}, r=0.665 & -\sigma_{q} / u_{*}=1.44+1.58(z / L)^{0.413}, r=0.650 \\
---\sigma_{q} / u_{*}=-3.29-1.00(-z / L)^{0.452}, r=0.637 & --\sigma_{q} / u_{*}=-2.36-1.59(z / L)^{0.332}, r=0.710 \\
& \text { - Pahlow et al., }[24] \sigma_{q} / u_{*}=2.0+4(z / L)^{0.6}
\end{aligned}
$$

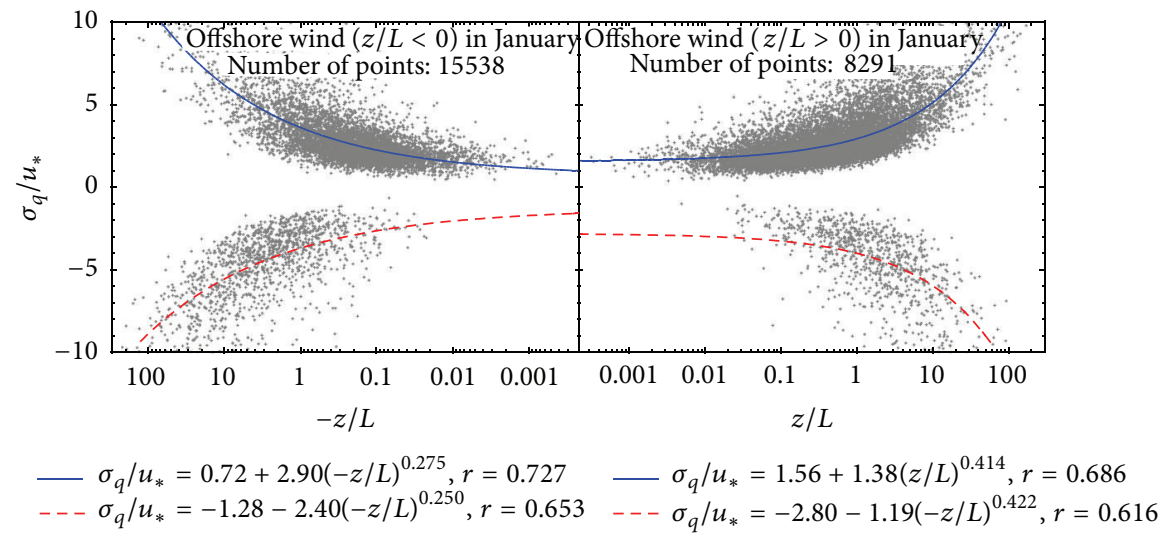

(b)

Figure 4: Continued. 

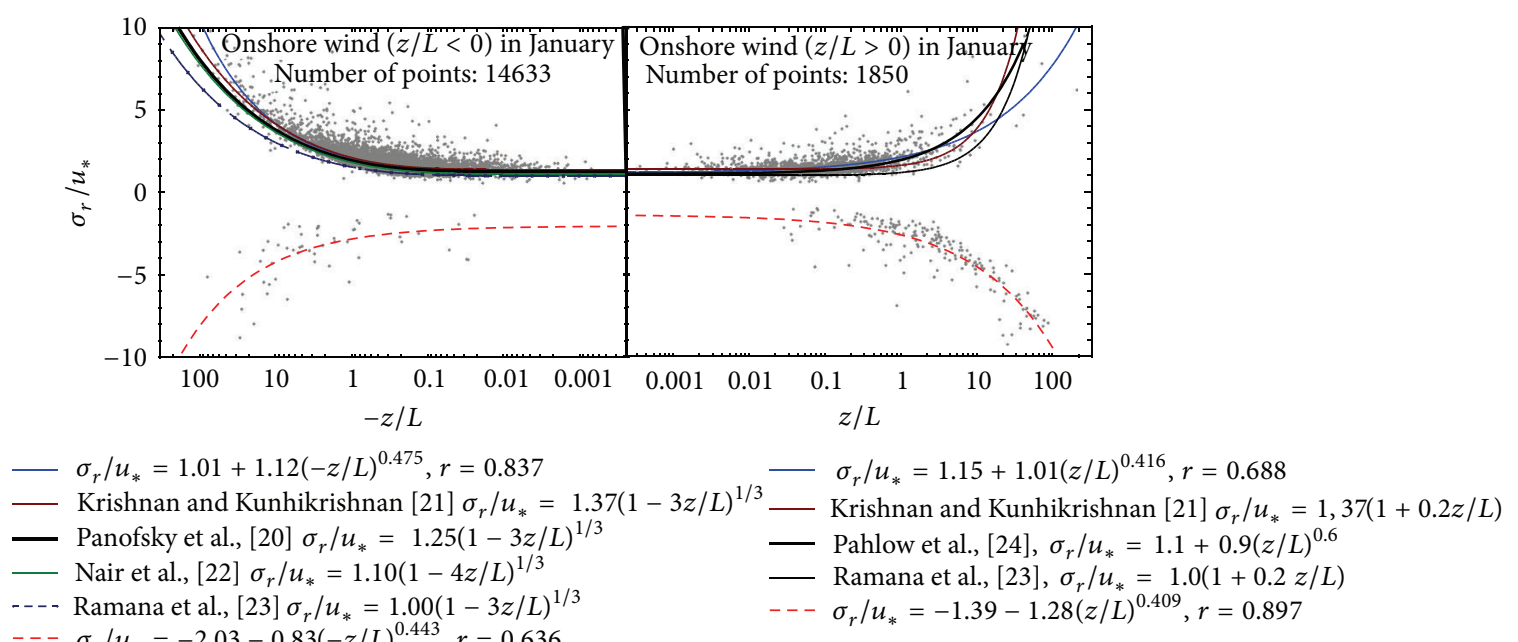

$--\sigma_{r} / u_{*}=-2.03-0.83(-z / L)^{0.443}, r=0.636$

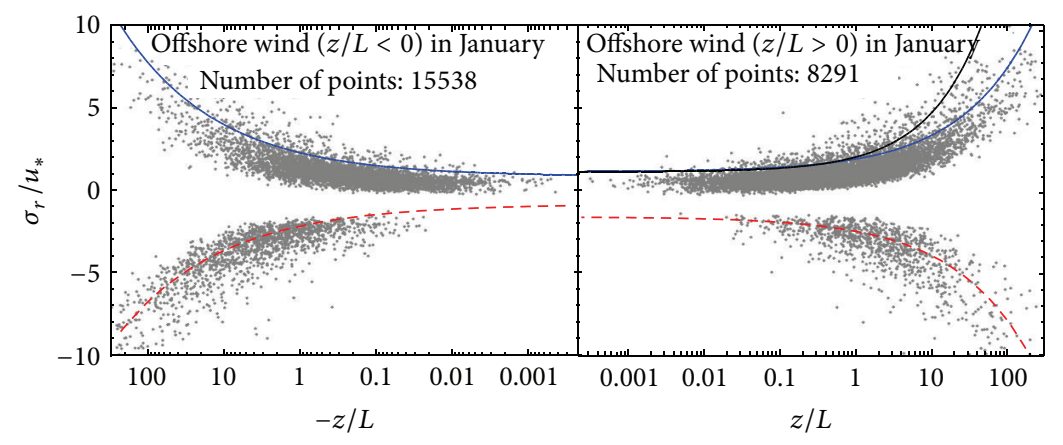

$-\sigma_{r} / u_{*}=0.83+1.43(-z / L)^{0.342}, r=0.826-\sigma_{r} / u_{*}=1.11+0.00(z / L)^{0.457}, r=0.819$
$---\sigma_{r} / u_{*}=-0.85-1.35(-z / L)^{0.323}, r=0.822--\sigma_{r} / u_{*}=-1.62-0.88(-z / L)^{0.428}, r=0.760$

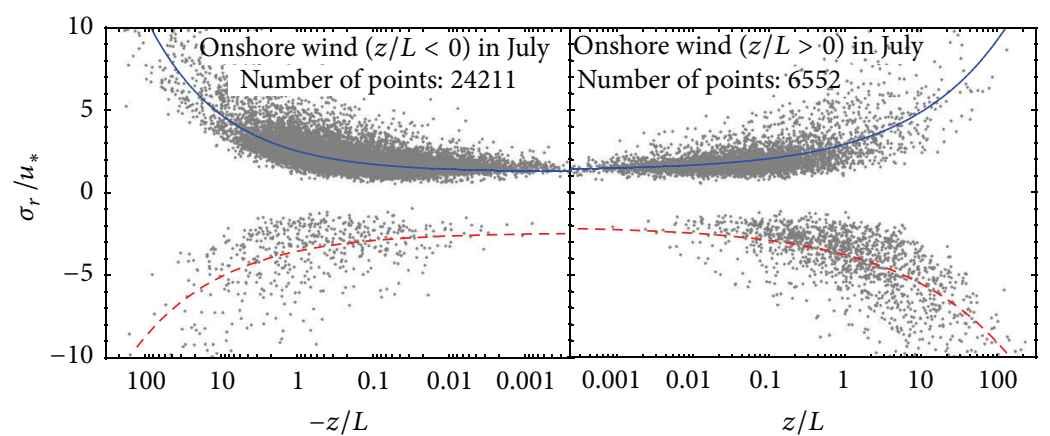

$-\sigma_{r} / u_{*}=1.25+1.34(-z / L)^{0.434}, r=0.716-\sigma_{r} / u_{*}=1.33+1.65(z / L)^{0.348}, r=0.652$
$---\sigma_{r} / u_{*}=-2.43-1.17(-z / L)^{0.434}, r=0.541--\sigma_{r} / u_{*}=-2.07-1.78(z / L)^{0.305}, r=0.683$

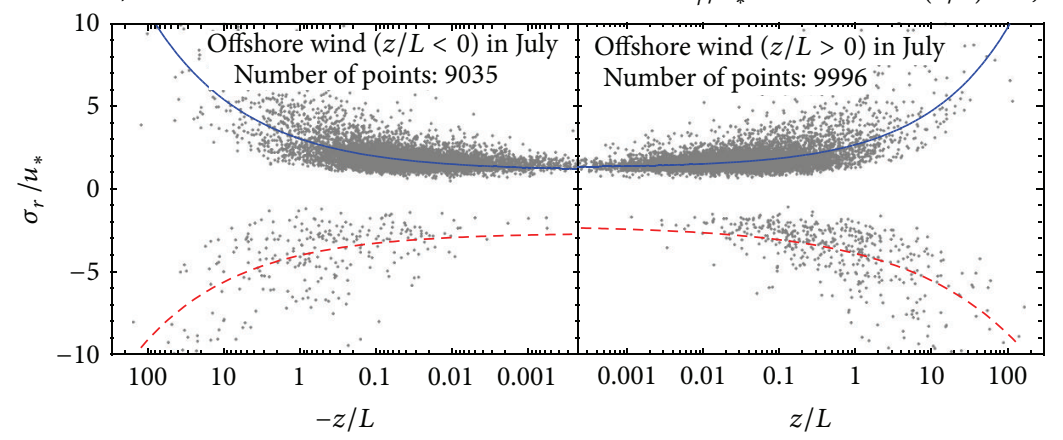

$-\sigma_{r} / u_{*}=1.11+1.92(-z / L)^{0.350}, r=0.664-\sigma_{r} / u_{*}=1.29+1.39(z / L)^{0.392}, r=0.593$

$-\sigma_{r} / u_{*}=1.11+1.92(-z / L), r=0.664-\sigma_{r} / u_{*}=1.29+1.39(z / L)^{0.392}, r=0.593$
$--\sigma_{r} / u_{*}=-2.66-1.36(-z / L)^{0.339}, r=0.550--\sigma_{r} / u_{*}=-2.22-1.69(z / L)^{0.294}, r=0.638$

(c)

FIGURE 4: Normalized standard deviation of (a) lateral, (b) longitudinal, and (c) vertical velocity components as a function of $z / L$. 
TABLE 1: Various relations among normalized standard deviations of vertical wind component to $z / L$.

\begin{tabular}{|c|c|c|c|}
\hline \multicolumn{2}{|c|}{ Unstable case $(z / L<0)$} & \multicolumn{2}{|c|}{ Stable case $(z / L>0)$} \\
\hline Panofsky et al., 1977 [21] & $\frac{\sigma_{w}}{u_{*}}=1.25+\left(1-3 \frac{z}{L}\right)^{1 / 3}$ & $\begin{array}{l}\text { Krishnan and } \\
\text { Kunhikrishnan, } 2002 \text { [22] }\end{array}$ & $\frac{\sigma_{w}}{u_{*}}=1.37\left(1+0.2 \frac{z}{L}\right)$ \\
\hline Nair et al., 1990 [23] & $\frac{\sigma_{w}^{*}}{u_{*}}=1.1+\left(1-4 \frac{z}{L}\right)^{1 / 3}$ & Ramana et al., 2004 [24] & $\frac{\sigma_{w}^{*}}{u_{*}}=1.0\left(1+0.2 \frac{z}{L}\right)$ \\
\hline $\begin{array}{l}\text { Krishnan and } \\
\text { Kunhikrishnan, } 2002 \text { [22] }\end{array}$ & $\frac{\sigma_{w}^{*}}{u_{*}}=1.37+\left(1-3 \frac{z}{L}\right)^{1 / 3}$ & $\begin{array}{l}\text { Present data fit through } \\
\text { power unity (for January) }\end{array}$ & $\frac{\sigma_{r}}{u_{*}}=1.6\left(1+0.345 \frac{z}{L}\right), r=0.41$ \\
\hline Ramana et al., 2004 [24] & $\frac{\sigma_{w}}{u_{*}}=1.0+\left(1-3 \frac{z}{L}\right)^{1 / 3}$ & $\begin{array}{l}\text { Power curve relation of the } \\
\text { form } y=a+b x^{c} \text { (for } \\
\text { January) }\end{array}$ & $\frac{\sigma_{r}}{u_{*}}=1.15+1.01 \frac{z}{L}^{0.415}, r=0.688$ \\
\hline $\begin{array}{l}\text { Present data fit through } 1 / 3 \\
\text { power relation (for January) }\end{array}$ & $\frac{\sigma_{r}}{u_{*}}=1.22+\left(1-4.53 \frac{z}{L}\right)^{1 / 3}, r=0.845$ & Pahlow et al., 2001 [25] & $\frac{\sigma_{w}}{u_{*}}=1.10+0.90 \frac{z}{L}^{0.6}$ \\
\hline $\begin{array}{l}\text { Power curve relation of the } \\
\text { form } y=a+b x^{c} \text { (for } \\
\text { January) }\end{array}$ & $\frac{\sigma_{r}}{u_{*}}=1.01+1.12\left(-\frac{z}{L}\right)^{0.475}, r=0.837$ & & \\
\hline
\end{tabular}

Mathematically mean resultant wind direction (MRWD) can be expressed by

$$
\text { MRWD }=\tan ^{-1}\left\{\frac{\sum_{i=1}^{N}\left(u_{i} / N\right)}{\sum_{i=1}^{N}\left(v_{i} / N\right)}\right\},
$$

where $u_{i}$ and $v_{i}$ are zonal and meridional wind components. $N$ is the number of observations. The structure of MRWD is shown in Figure 8. Due to the orientation of the coastline, clockwise wind directions which fall between $145^{\circ}$ and $325^{\circ}$ are considered as sea-breeze flow and from $325^{\circ}$ to $145^{\circ}$ are in the land-breeze regime. The changeover from sea to land breeze and land to sea breeze is well remarkable from October to May through January. The sea-breeze onset takes place around $1000 \mathrm{IST}$ (IST $=\mathrm{GMT}+5 \mathrm{hr} 30 \mathrm{~min}$ ), whereas the land-breeze onset is around 2000 IST during January to May and 1800 IST during October to December. In the SW monsoon months, between 1030 and 1930 IST, the sea breeze is in westerly direction and north-north-westerly during other timings. The north-north-westerly wind direction may be attributed to the interaction among the dominant synoptic scale monsoon flow and the mesoscale changes in the thermal environment due to land-sea temperature contrast.

Momentum flux $(M)$ (Figure 9) shows higher negativity during sea-breeze flow, which means that the sea-breeze flow generated shearing force that transmits the $M$ downwards and the transfer mechanism was explained by Oke [44]. Due to the effect of forced mechanical convection generated by the surface roughness and mutual shearing between air flow layers moving at different velocities, turbulent eddies are continually moving up and down with respect to the measuring level. An eddy arriving at the measurement level developed above will, upon mixing, impart a net increase in velocity (and hence momentum) and thereby the anemometer would see this downdraft as an increase in wind speed during the course of a day as observed in mean scalar wind speed. The net effect of both updrafts and downdrafts is always to maintain a net flux of momentum downwards and results in negative values. Figure 10 represents the structure of stress off-wind angle $(\alpha)$, which is low during onshore flow and high in offshore wind regime. $\alpha$ value provides the orientation of wind direction vector with respect to shear vector and vice versa. The mutual orientation of wind and stress vector as coterminus/collinear corresponds to $+\mathrm{ve} /-\mathrm{ve} M$ values, respectively.

By adding mean resultant wind direction and the mean stress off-wind angle, the mean direction of stress is computed [43] in the meteorological coordinate system as depicted in Figure 11. For example, for a wind direction of $180^{\circ}$ (southerly) and off-wind stress angle of $45^{\circ}$, the direction of the stress vector will be from $225^{\circ}$ (southwesterly). The most dominant mean direction of the stress for this station is from about $242^{\circ}$ during the daytime portion of SW monsoon season.

\section{Mean Structure of Wind and Turbulent Parameters}

In scalar wind speed (Figure 12), maxima are observed in the sea-breeze regime of the order of $\geq 2 \mathrm{~m} \mathrm{~s}^{-1}$ and above and feeble wind speeds are observed during the land-breeze regime. The highest scalar speeds in the diurnal course correspond to the highest negativity in momentum flux values.

Figure 13 shows $u_{*}$ structure. During situations where turbulence created or modulated by wind shear near the ground is larger, the magnitude of the surface Reynolds stress is of larger and thereby higher $u_{*}$ values. Over the station, high $u_{*}$ is encountered during sea-breeze regime and highest values are observed of the order $0.35 \mathrm{~m} \mathrm{~s}^{-1}$.

Large $u_{*}$ values during sea breeze compared to land breeze indirectly explain that wind shear generated by sea breeze is higher than that produced by land breeze.

Due to mechanical and thermal convection with respect to stability conditions, both +ve and -ve values are observed in the vertical wind component ( $w$ component) (Figure 14). Higher -ve values are seen between 1200 IST and 1600 IST in the sea-breeze regime, except from May to July. Before 0900 IST and after 1700 IST + ve values are observed due to suppressed thermal activity. -ve values are attributed by the net downward flux of momentum created by shearing stress among layers. The portions of the greatest -ve 


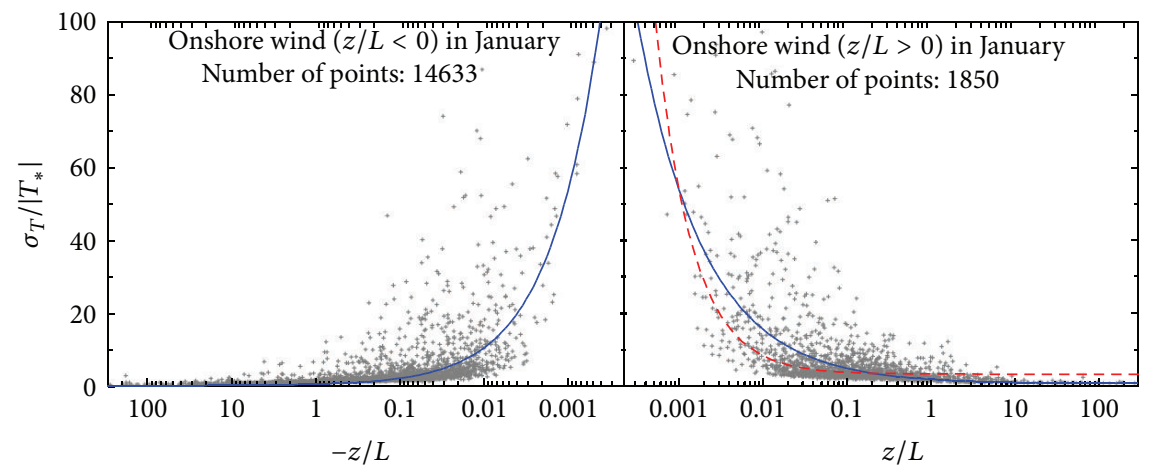

$\sigma_{t} /\left|T_{*}\right|=0.354+0.386(-z / L)^{-0.713}, r=0.744-\sigma_{t} /\left|T_{*}\right|=0.648+1.18(z / L)^{-0.552}, r=0.743$

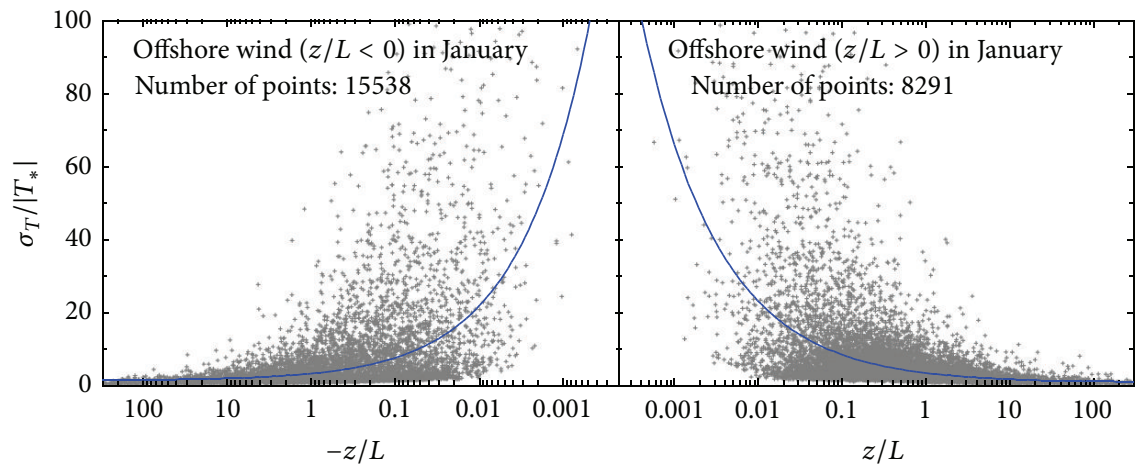

$-\sigma_{t} /\left|T_{*}\right|=1.45+1.88(-z / L)^{-0.518}, r=0.472-\sigma_{t} /\left|T_{*}\right|=0.916+2.58(z / L)^{-0.467}, r=0.513$

(a)

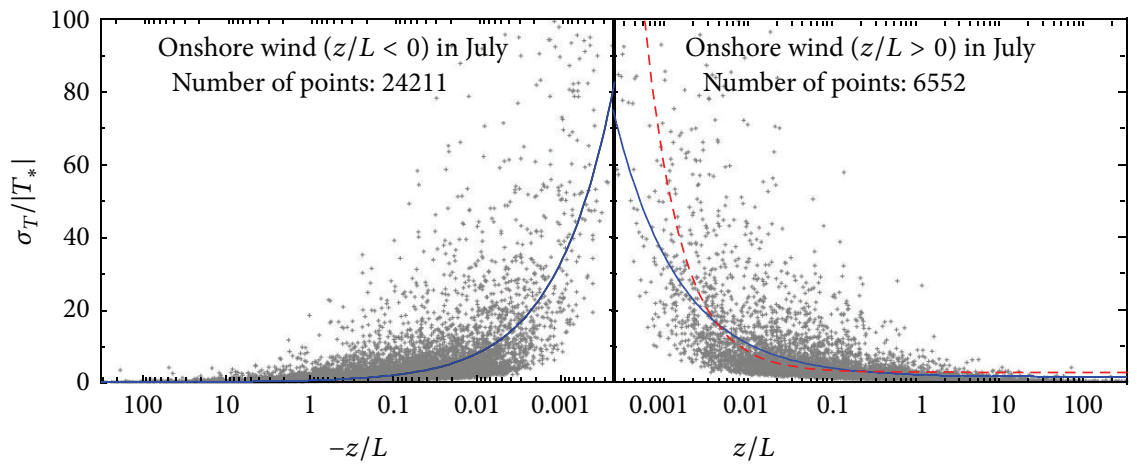

$-\sigma_{t} /\left|T_{*}\right|=0.337+0.432(-z / L)^{-0.624}, r=0.790-\sigma_{t} /\left|T_{*}\right|=1.41+0.650(-z / L)^{-0.562}, r=0.672$

- - Pahlow et al., [24] $\sigma_{t} /\left|T_{*}\right|=3.0+0.05(z / L)^{-1}$

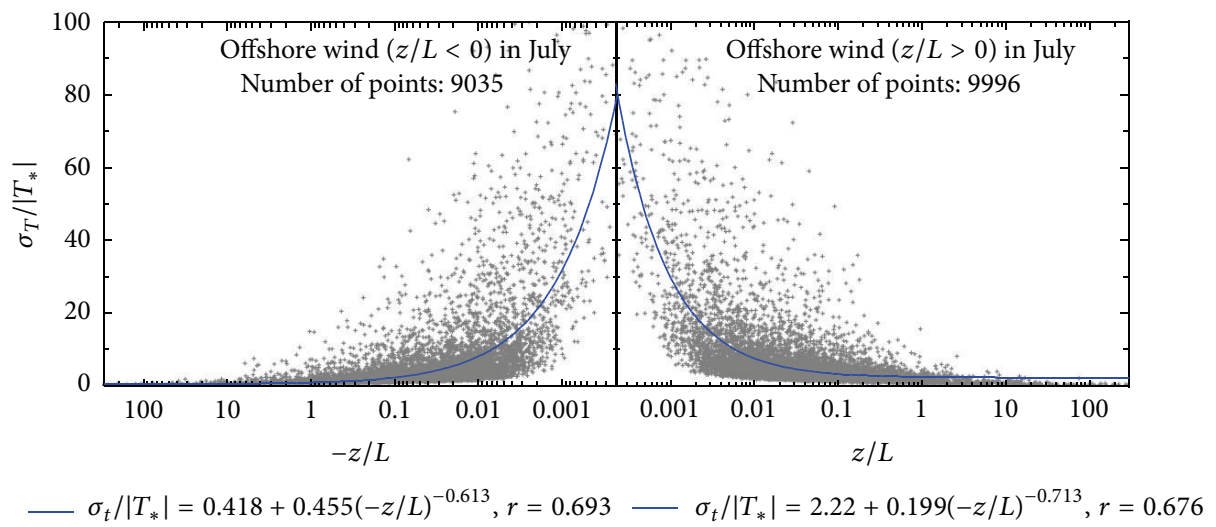

(b)

FIGURE 5: Normalized standard deviation of absolute value of sonic temperature as a function of $z / L$ for January and July. 


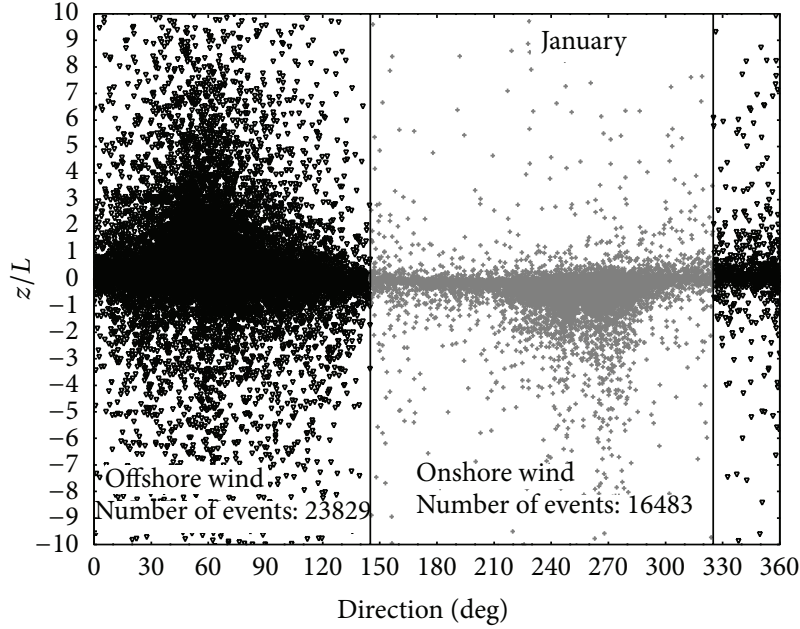

(a)

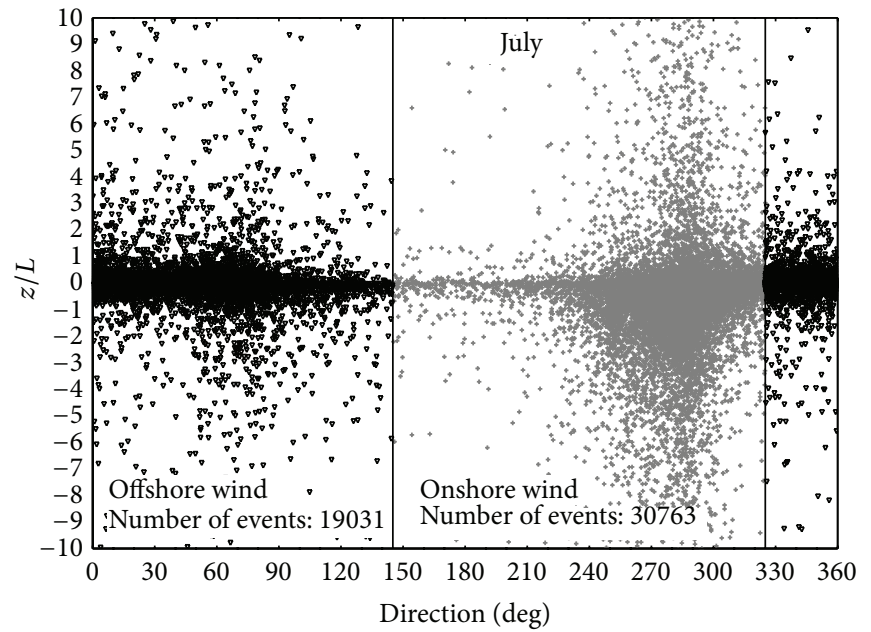

(b)

FIGURE 6: Scatter plot of $z / L$ and wind direction for two representative months.

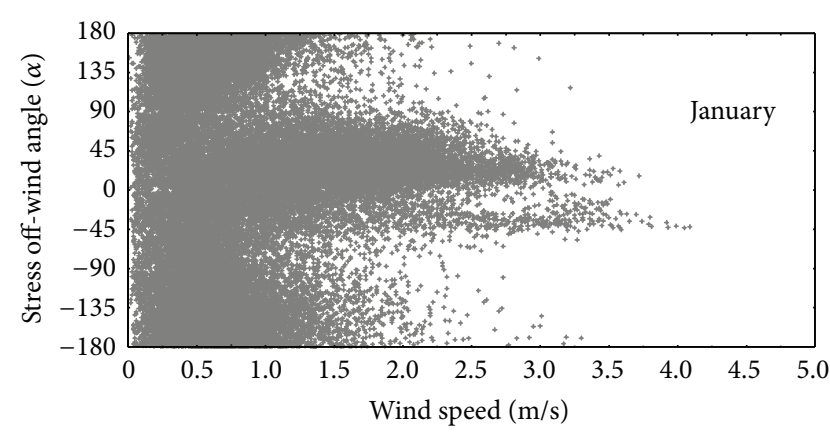

(a)

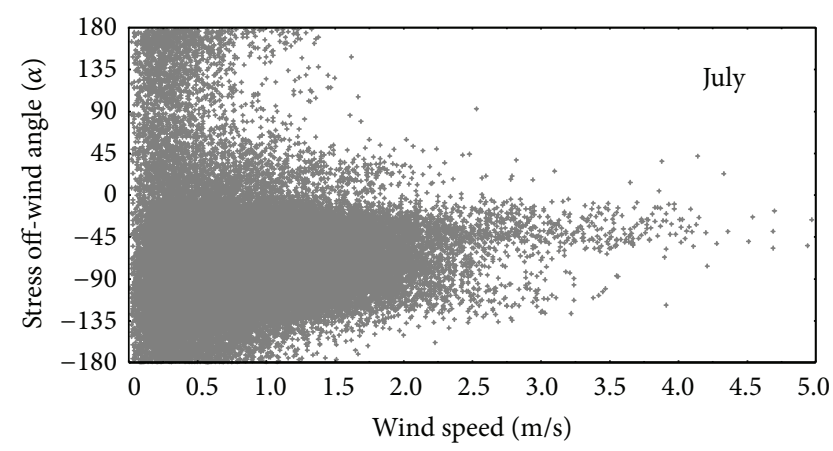

(b)

FIGURE 7: Scatter plot of stress off-wind angle $(\alpha)$ and wind speed.
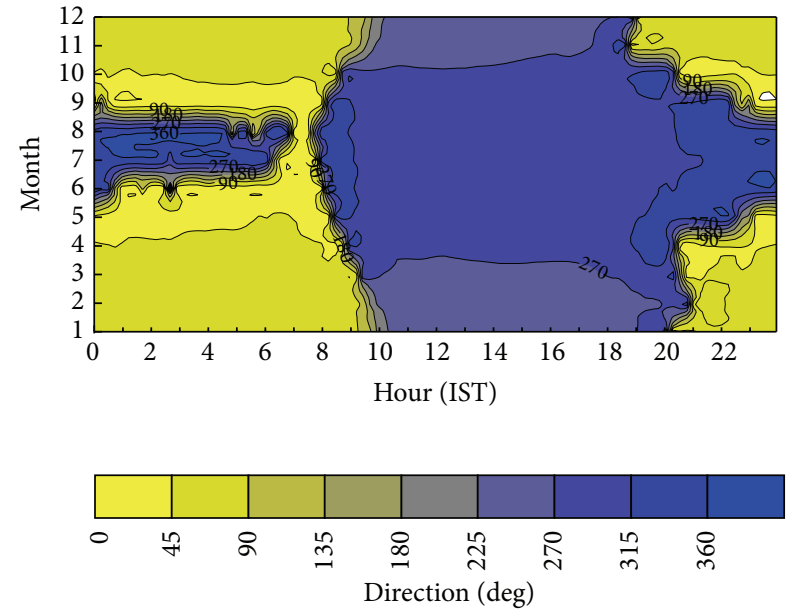

FIGURE 8: Structure mean resultant wind direction.

values are associated with the greatest values in the net downward momentum flux. The opposite is true for +ve values.
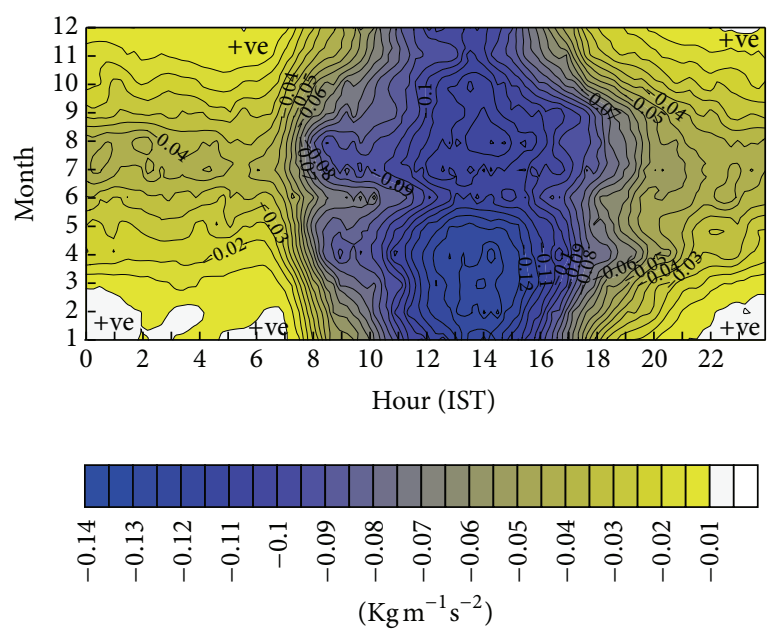

FIGURE 9: Mean structure of momentum flux $(M)$.

Systematic occurrences of Obukhov length values (Figure 15) make a quantitative interpretation on mechanical turbulence and heat convection. From 0730 IST to 


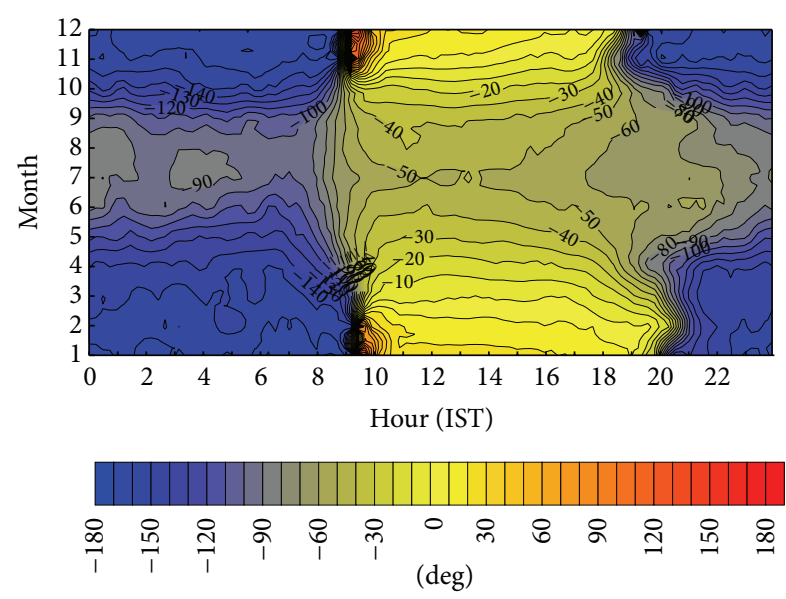

Figure 10: Mean structure of stress off-wind angle $(\alpha)$.
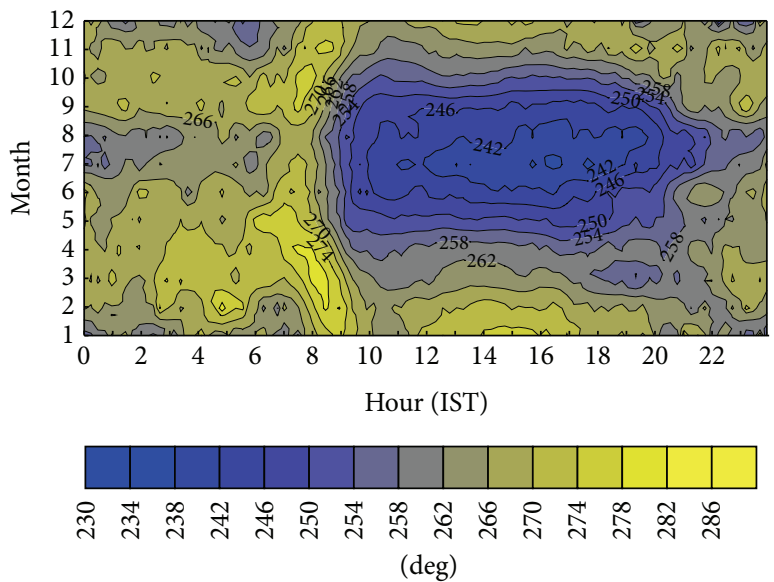

FIGURE 11: Mean direction of stress computed in the meteorological coordinate system.

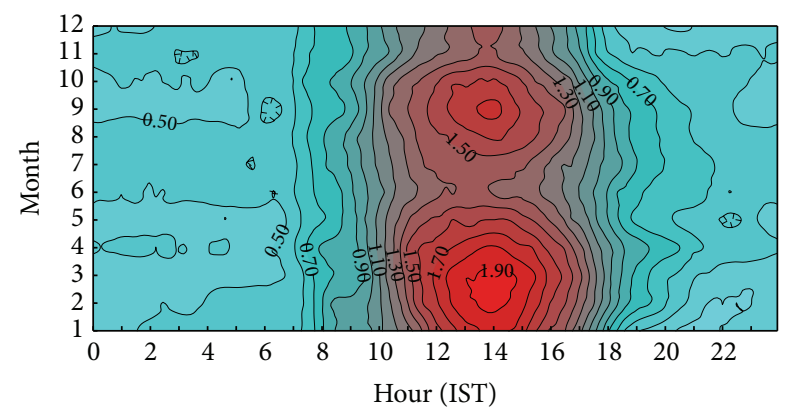

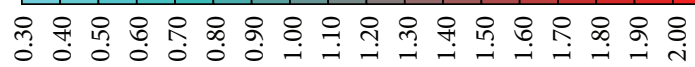
$\left(\mathrm{ms}^{-1}\right)$

FIgURE 12: Mean scalar wind speed.

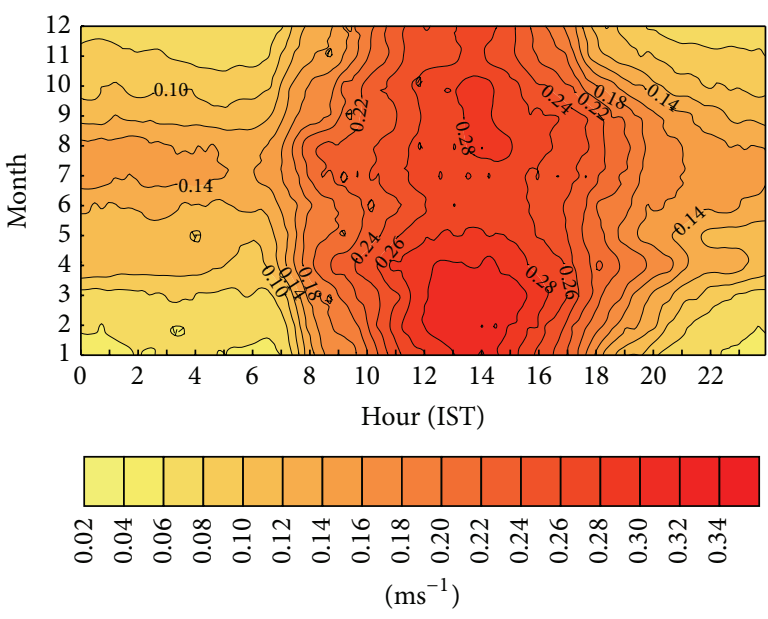

FIGURE 13: Mean structure of frictional velocity.

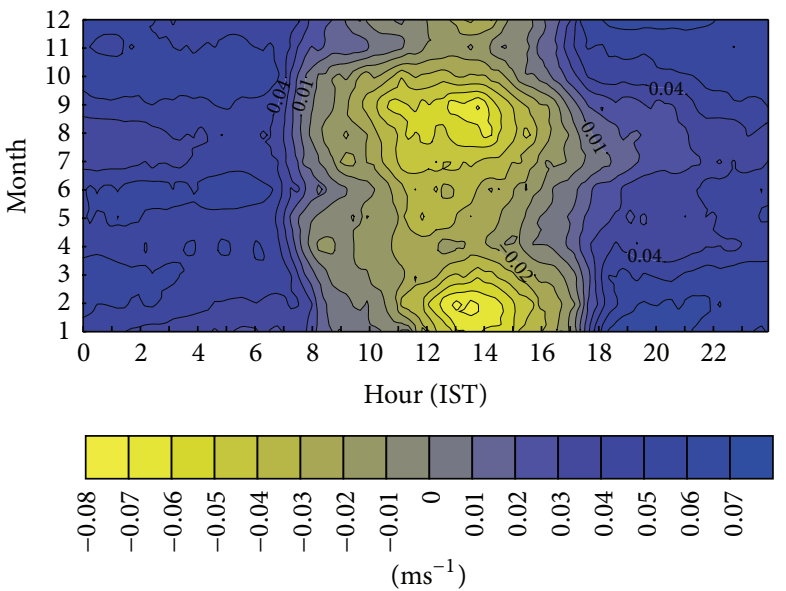

FIGURE 14: Mean structure of vertical wind component.
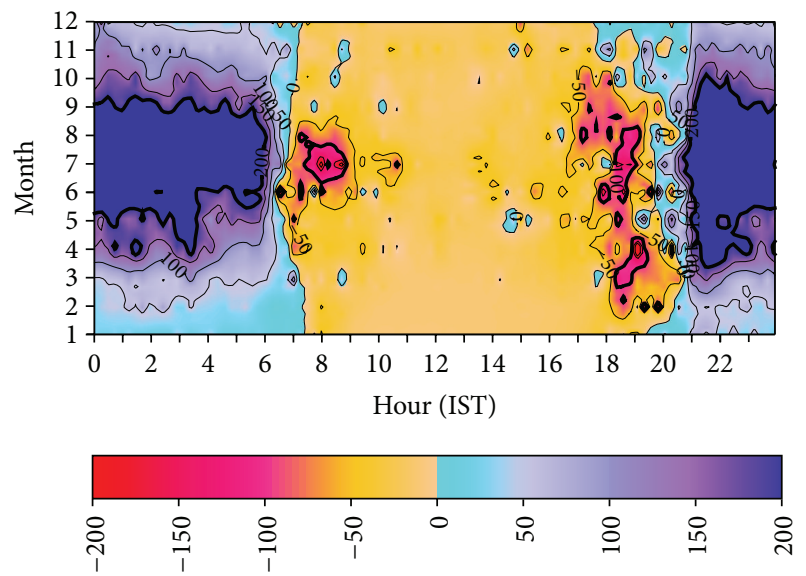

(m)

FIGURE 15: Mean structure of Obukhov Length $(L)$. 
TABLE 2: $L$ values under different stability characteristics.

\begin{tabular}{lc}
\hline$L$ & Characteristics \\
\hline$>200$ & Neutral \\
50 to 100 & Weakly stable \\
0 to 50 & Highly stable \\
0 to -50 & Highly unstable \\
-50 to -100 & Weakly unstable \\
$<-100$ & Neutral \\
\hline
\end{tabular}

$1800 / 1900$ IST it is observed that the $L$ values are negative and in the rest of the periods the values are positive. Strong/light negative $L$ values are the characteristics of highly/weakly unstable conditions and strong/light positive $L$ values represent highly/weakly stable conditions. A quantitative interpretation of $L$ may be inferred from Table 2. The changeover from negative to positive values and vice versa happens around 1930 IST and about 0730 IST, respectively. It is interesting to note the occurrence of neutral regimes for $<-100$ and $>200$ (corresponding to $z / L \approx 0.03$ and 0.02 ) values (presented with bold contour) is mostly during evening, night, and early hours of the day till about 0900 IST in SW monsoon. Overcast skies with high wind speeds are very common during these hours.

Turbulent sensible heat flux $(H)$ values (Figure 16) in winter $(D, J, F)$, summer $(M, A)$, and premonsoon month May are higher than the SW monsoon $(J, J, A, S)$ and NE monsoon $(O, N)$ solely related to less cloudiness during former compared to later months. Another reason of $H$ increase around March and September is due to equinoctial solar activity. The highest values in turbulent heat flux during winter are of the order of above $280 \mathrm{~W} \mathrm{~cm}^{-2}$. During the course of a day, the values increase steadily about an hour after the sunrise and decrease from about 1600 IST onwards. From the observations it is clear that heat flux values are totally controlled by cloudiness and solar activity.

Mean variation of $C_{D}$ is shown in Figure 17. The lowest values of less than 0.04 are observed during the sea-breeze regime between 1300 and 1600 IST. Though the wind speed and frictional velocity values are high during this period, increase in $C_{D}$ is not observed. The present result demonstrates the dominance of frictional velocity over the scalar speeds during daytime which results in low $C_{D}$ values (6) which may be inferred as changes in $C_{D}$ when the wind speed is rapid compared to $u_{*}$ [22].

Variations in turbulent intensities (longitudinal, i.e., collinear to the wind direction, transverse, i.e., perpendicular to the longitudinal and in the vertical) provide (Figures 18(a), 18(b), and 18(c)) excellent insight into SBL eddy formations. Turbulent intensities during the course of the day show similar features. This can be interpreted that an eddy which influences the measuring level will have equal contribution among the three perpendicular wind components. For an operational way to check turbulence, turbulent kinetic energy (TKE) helps to estimate the scale depth of eddy formation. Larger TKE indicates a higher intensity of turbulence. In the cascaded form of atmospheric energy spectra distribution,
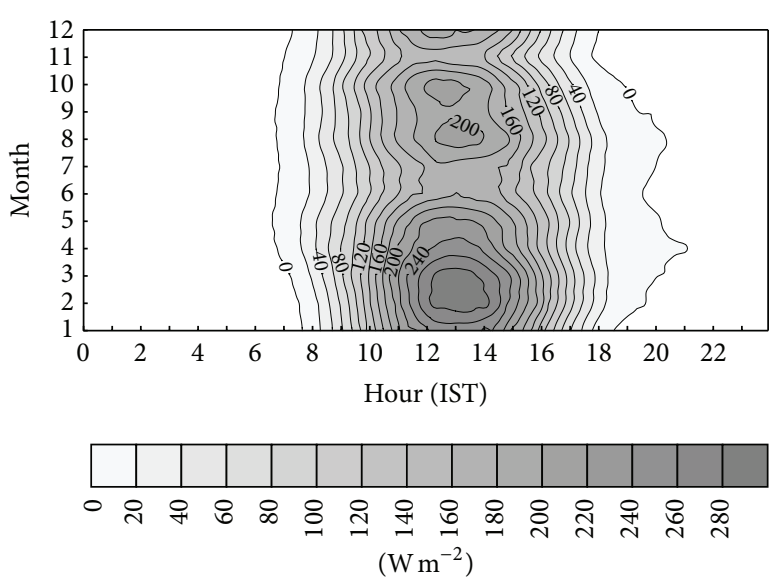

FIgURE 16: Structure of turbulent sensible heat flux values $(H)$.

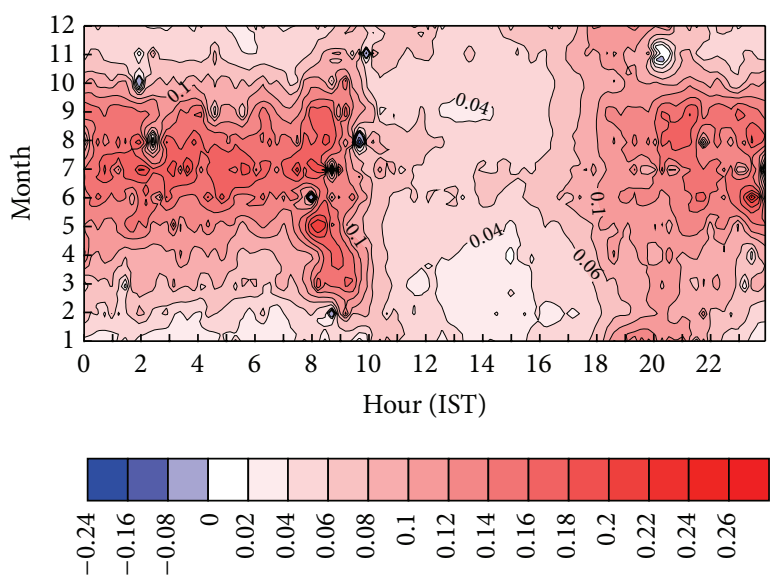

FIGURE 17: Structure of mean drag coefficient $\left(C_{D}\right)$.

the TKE dissipation which takes place for internal energy of the system is through molecular viscosity. Mathematically

$$
\mathrm{TKE}=\frac{1}{2}\left(\sigma_{u}^{2}+\sigma_{v}^{2}+\sigma_{w}^{2}\right),
$$

where $\sigma_{u}, \sigma_{v}, \sigma_{w}$ are the standard deviations in wind components. Willis and Deardorff [45] have explained that, with a condition for standard deviation of scalar winds, $\sigma_{s}<0.5$ times of mean scalar wind speed $(v)$, an eddy of diameter $\lambda$ has negligible changes; then $P=\lambda / v$ (or $\lambda=P v$ ) for the specific interval of time $P$ (also see Stull [46]). We assumed the passage of an eddy or part of the eddy of size $(\lambda)$ past the sensor within a fixed time gap of $P=5 \mathrm{~min}$ with an average scalar speed of $v$ for cases $\sigma_{s}<0.5 v$. By inputting $v$, $\sigma_{u}, \sigma_{v}, \sigma_{w}$, and $P$, TKE and $\lambda$ can be estimated. TKE and eddy distribution in July and January are shown in Figures 19(a) and 19(b). Due to strong convection, high value of TKE/eddy size and eddy sizes are seen in July unlike air subsidence dominant winter month, January. Occurrences of TKE/eddy size of more than 2 correspond to eddy size above $600 \mathrm{~m}$.

Diurnal variation of TKE and eddy size on a typical day is affected by mesoscale phenomena like sea/land breezes; thunderstorms are depicted in Figure 20. Abrupt increase 

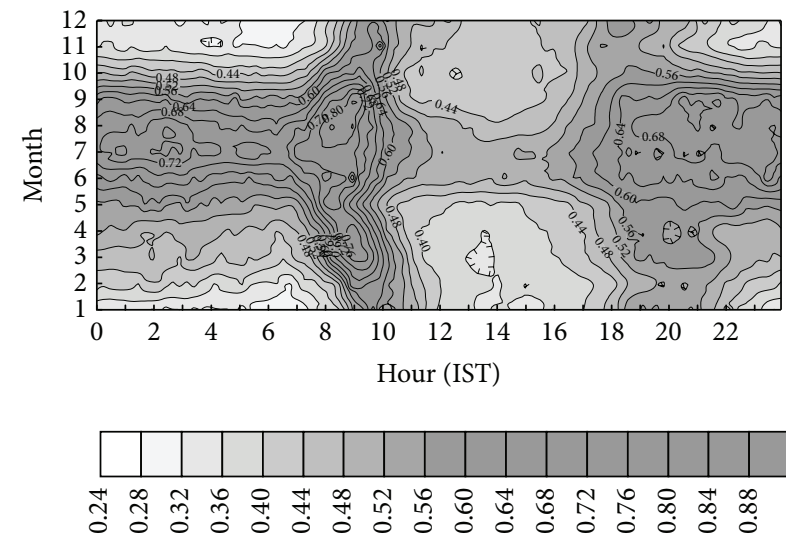

(a)

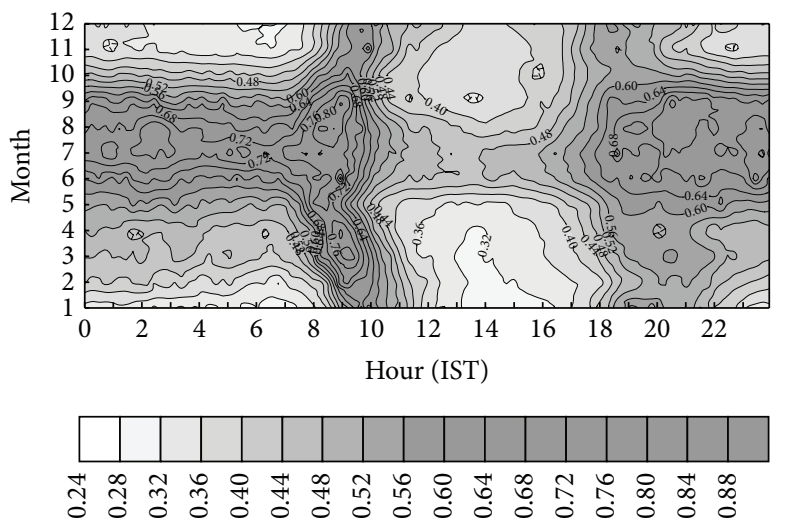

(b)

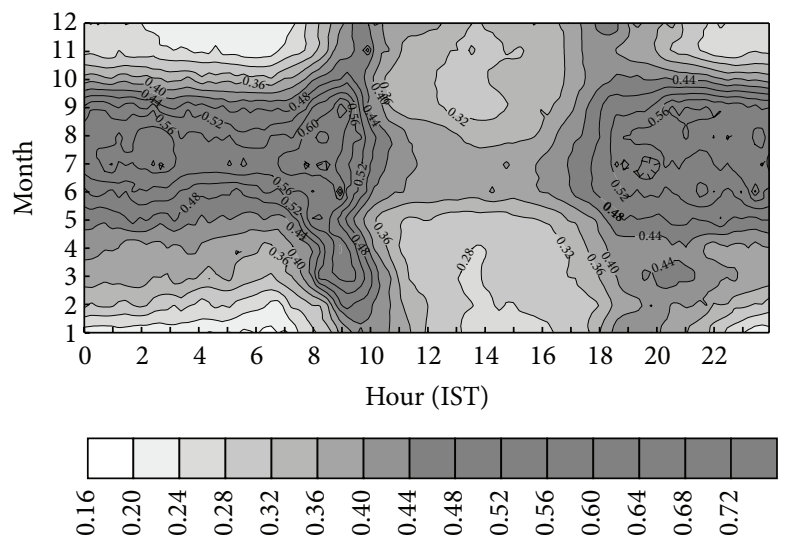

(c)

FIGURE 18: Similarity in variations of (a) longitudinal turbulent intensity, (b) transverse turbulent intensity, and (c) vertical turbulent intensity.

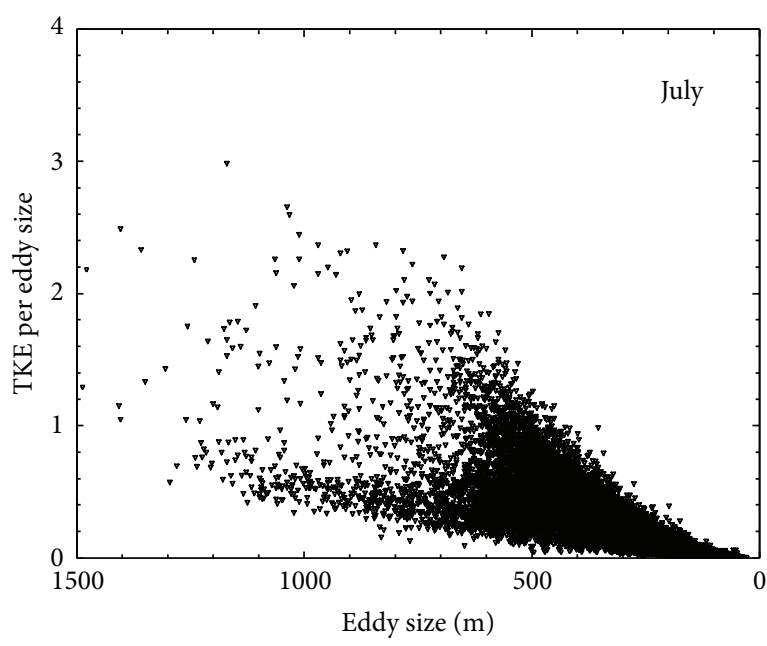

(a)

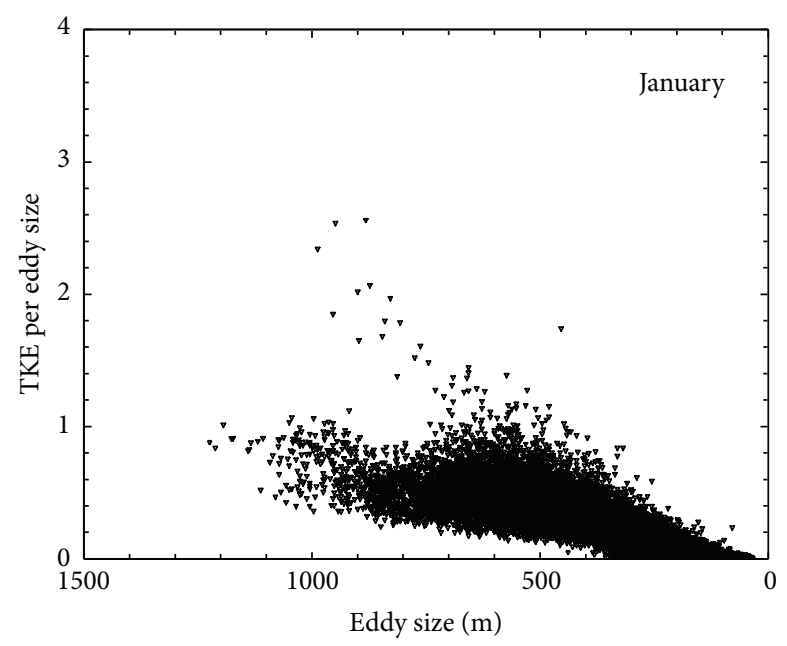

(b)

FIGURE 19: (a) Turbulent kinetic energy (TKE) and eddy size distribution in July and (b) January. 


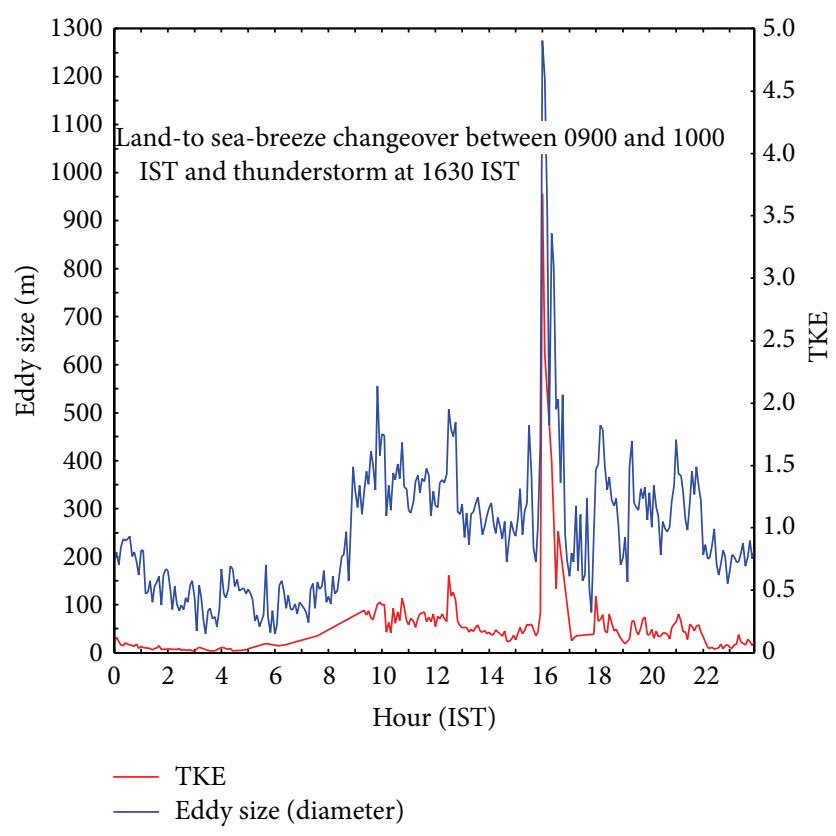

FIGURE 20: Diurnal variation of TKE and eddy size on May 09, 2010.

of TKE and thereby eddy size has been observed with changeover of land breeze to sea breeze (around 0900 IST) as well as a sudden shoot-up of TKE and eddy size during the passage of a thunderstorm (1630 IST).

\section{Standard Deviation of Wind Direction and Wind Steadiness Factor}

As wind direction is a circular function with a discontinuity of scale at $360^{\circ}$, special treatment is required to arrive the standard deviation of wind directions $\left(\sigma_{\theta}\right)$ [47-50]. By the Ackermann [47] method, wind direction standard deviation is computed for an hour by using 12 five-minute interval wind data on speed and direction. In the same set of data wind steadiness factor (WSF) is also determined. WSF is a general quantitative meteorological technique to estimate the steadiness of wind direction [51]. Steadiness factor (expressed in \%) is defined as the ratio of mean resultant wind speed (MRWS) to mean scalar wind speed (MSWS):

$$
\begin{gathered}
\text { MSWS }=\sum_{i=1}^{N} \frac{V_{i}}{N}, \\
\text { MRWS }=\sqrt{\sum_{i=1}^{N}\left(\frac{u_{i}}{N}\right)^{2}+\sum_{i=1}^{N}\left(\frac{v_{i}}{N}\right)^{2}}, \\
\operatorname{WSF}(\%)=\frac{\operatorname{MRWS}}{\operatorname{MSWS}} \times 100,
\end{gathered}
$$

where $V_{i}, u_{i}, v_{i}$, and $N$ are scalar wind speed, zonal component, meridional component, and number of observations, respectively. Mean structure of wind direction standard

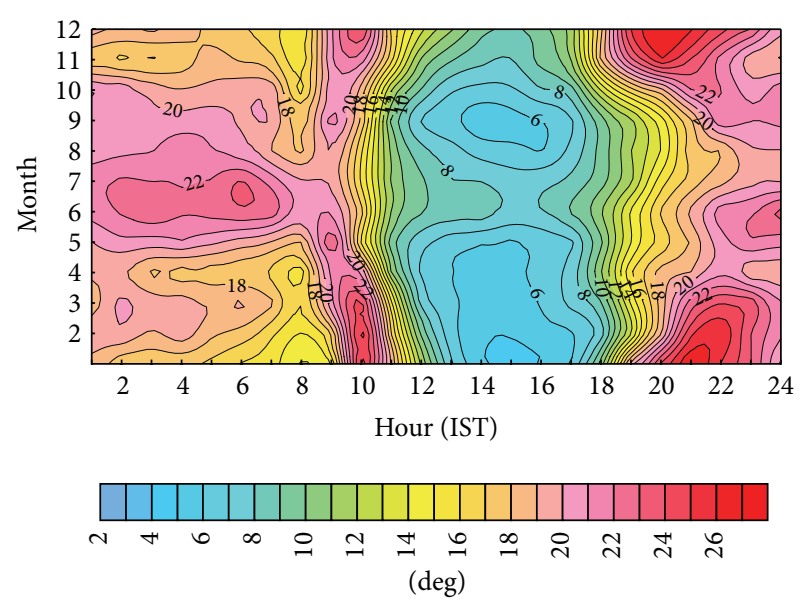

FIGURE 21: Structure of standard deviation of wind direction $\left(\sigma_{\theta}\right)$.

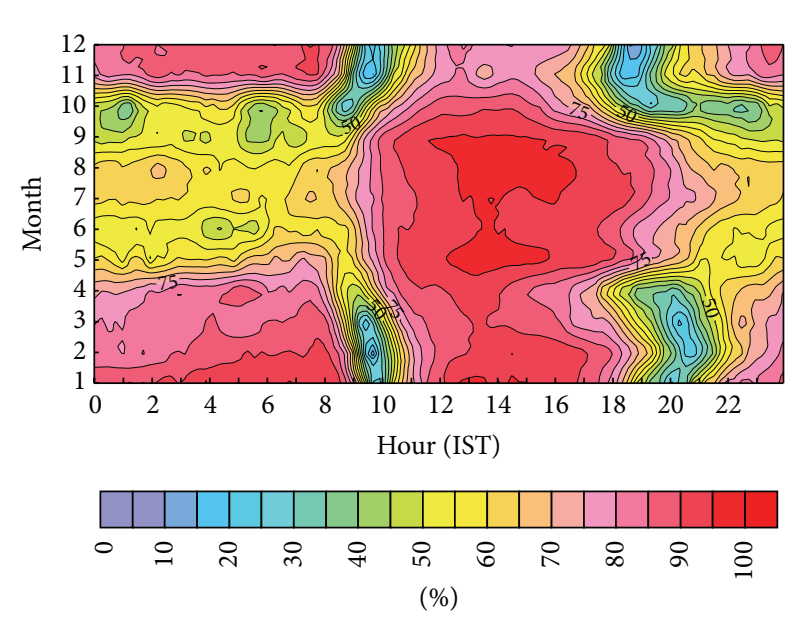

FigURE 22: Structure of wind steadiness factor (WSF).

deviation and WSF are shown in Figures 21 and 22, respectively. Inverse proportionality is detected among $\sigma_{\theta}$ and WSF as noticed by Namboodiri [20]. Standard deviation in wind direction $\left(\sigma_{\theta}\right)$ provides a tool for atmospheric stability estimate for atmospheric dispersion modeling. To know the interaction between mesoscale onshore/offshore flow and the prevailing seasonal flow, diurnal $\sigma_{\theta}$ climatologies are compared between the west (Thumba) and east (Sriharikota) coast of the Peninsular India for July. In July both stations are under the influence of the same synoptic scale SW monsoonal flow. It is realized that whenever the mesoscale onshore/offshore flow and the synoptic scale seasonal flow are in opposite directions, the resultant $\sigma_{\theta}$ are high unlike low values for the same direction interactions (Figure 23). Half hourly variations of $\sigma_{\theta}$ and WSF are examined as a case study for an overhead quasistationary thunderstorm formation on May 09, 2010 from 1500 IST to 2100 IST (Figure 24). During the thunderstorm event, $\sigma_{\theta}$ increase and WSF decrease are observed. 

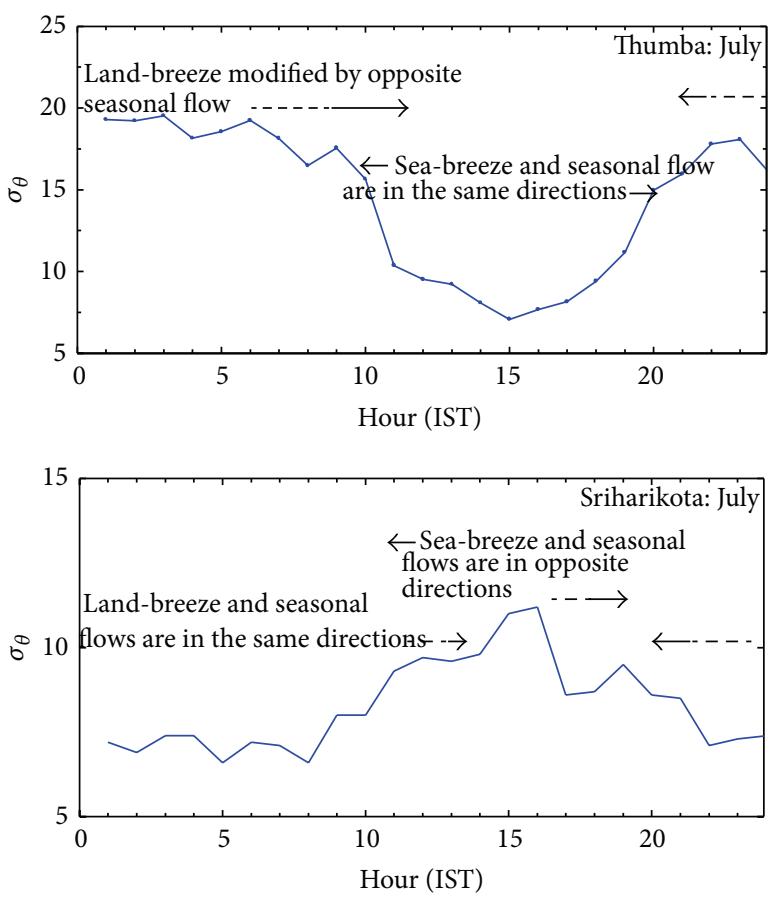

Figure 23: $\sigma_{\theta}$ variations due to mesoscale flow interaction with synoptic-scale flow.

\section{Bivariate Normal Distribution (BND) Wind Model}

When $u$ and $v$ are correlated, it is a necessary but not a sufficient condition for the marginal distribution $f(u)$ and $f(v)$ to be normal distribution and the joint distribution to be BND. Problems dealing with wind components require the integral of elliptical BND. An elaborate discussion on BND applicable to SBL wind components and the stepwise construction procedures can be seen in Namboodiri et al. [52]. The probability density function (pdf) for BND is

$$
\begin{aligned}
& P(u, v) \\
& =\frac{1}{2 \pi \sigma_{u} \sigma_{v} \sqrt{\left(1-\rho_{u v}^{2}\right)}} \\
& \quad \times \exp \left[-\frac{1}{2\left(1-\rho_{u v}^{2}\right)}\right. \\
& \quad \times\left(\frac{(u-U)^{2}}{\sigma_{u}^{2}}-\frac{2 \rho_{u v}(u-U)(v-V)}{\sigma_{u v}}\right. \\
& -\infty \leq u \leq \infty, \quad-\infty \leq v \leq \infty .
\end{aligned}
$$

The pdf can be derived by setting

$$
\left[\frac{(u-U)^{2}}{\sigma_{u}^{2}}-\frac{2 \rho_{u v}(u-U)(v-V)}{\sigma_{u v}}+\frac{(v-V)^{2}}{\sigma_{v}^{2}}\right]=\lambda^{2} .
$$

$U, V, \sigma_{u}, \sigma_{v}$, and $\rho_{u v}$ represent mean value of the component $u$, mean value of the component $v$, standard deviation of $u$, standard deviation of $v$, and correlation coefficient among $u$ and $v$, respectively.

Equation (13) is recognized as a family of ellipses depending on the values of $\lambda^{2}$. The density function has constant values on these ellipses. So the ellipses generated out of (13) are referred to as ellipses of equal probability. The percentile ellipses can be generated based on $\lambda$ value variations as

$$
\lambda=\sqrt{2}\{\sqrt{-\ln (1-\mathbf{P})}\},
$$

where $\mathbf{P}$ is the probability. For $90 \%$ probability ellipse $\lambda=2.146$ and the same probability computations and thereby ellipse constructions are made in BND of wind components generated in the study. BND ellipses are available from Figures 25(a) and 25(b) for winter and SW monsoon months. Ellipse orientation is based on the prevailing wind direction of the season and thereby ellipses pertaining to same season are depicted in the same diagram. The larger measure of major axes in ellipses shows the dominance of zonal components. The ellipse quadrant having more area possesses more numbers of occurrences of events.

\section{Structure of Surface Roughness Parameter $\left(z_{0}\right)$}

$z_{0}$ values are computed by (1) by taking every 5 min values of different variables in the equation by considering unstable $(z / L<0)$ cases. Mean monthly structure of roughness parameter is in Figure 26, which shows the lowest and highest value regimes in sea breeze and land breeze, respectively. Mean structure of $z_{0}$ ranges from $0.02 \mathrm{~m}$ to $0.24 \mathrm{~m}$ with respect to wind direction. High values or imaginary values (not presented) mostly during land breeze and are associated with $z / L>0 . z_{0}$ values are computed for 5 min interval unstable case $(z / L<0)$ raw data by using (1). $z_{0}$ values observed during $z / L>0$ have shown high or imaginary due to exponentiation in (1). Polar plot of 319656 numbers of $z_{0}$ values with respect to wind direction is shown in Figure 27 and most of the $z_{0}$ values are within $0.5 \mathrm{~m}$, a representative value for sea coastline from the sonic anemometer measurements at $3.3 \mathrm{~m}$ level. For every $10^{\circ}$ wind direction interval mean and standard deviation $(\sigma)$ of $z_{0}$ are computed and the mean, mean $+\sigma$, mean $+2 \sigma$, and (mean $+3 \sigma)$, plots are incorporated as thick lines in the polar diagram. A line shows $145^{\circ}-325^{\circ}$ is also made to demark sea-coastline orientation. Low and high $z_{0}$ values are clearly observed during onshore and offshore flows, respectively, with sharp decrease around $242^{\circ}$ shown by an arrow. This interesting observation tells that minimization of $z_{0}$ values may not be the result of onshore flow perpendicular to the coast but due to orientation of the wind stress vector $\left(242^{\circ}\right)$. Buildup in $z_{0}$ starts as nearing to the coast at $325^{\circ}$ orientation due to land frictional effect and maxima in $z_{0}$ happen around $35^{\circ}$ azimuth. Onshore winds are arriving to the observation point through medium sized coconut plantations. Another low roughness regime encountered around $125^{\circ}$ is attributed to the barren sandy land in the SE sector of the anemometer. High roughness 


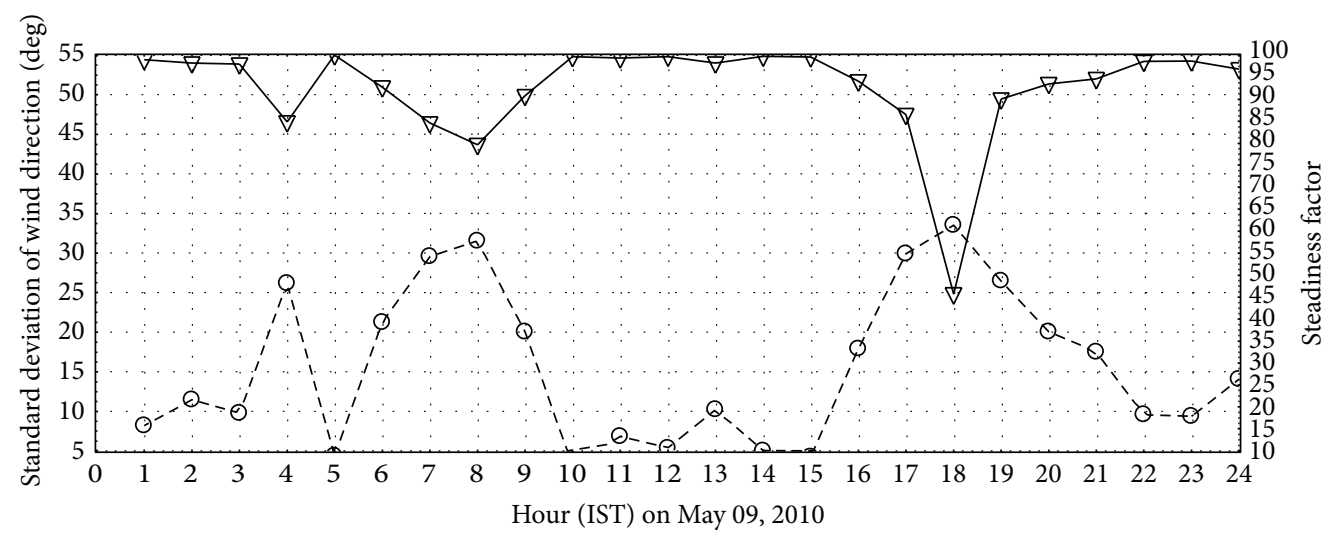

$\circ-0 \sigma_{\theta}$

$\nabla$ Steadiness factor

FIGURE 24: Half hourly variations of $\sigma_{\theta}$ and WSF during an overhead quasistationary thunderstorm formation on May 09,2010 from 1500 to 2100 IST with severity around 1800 IST.

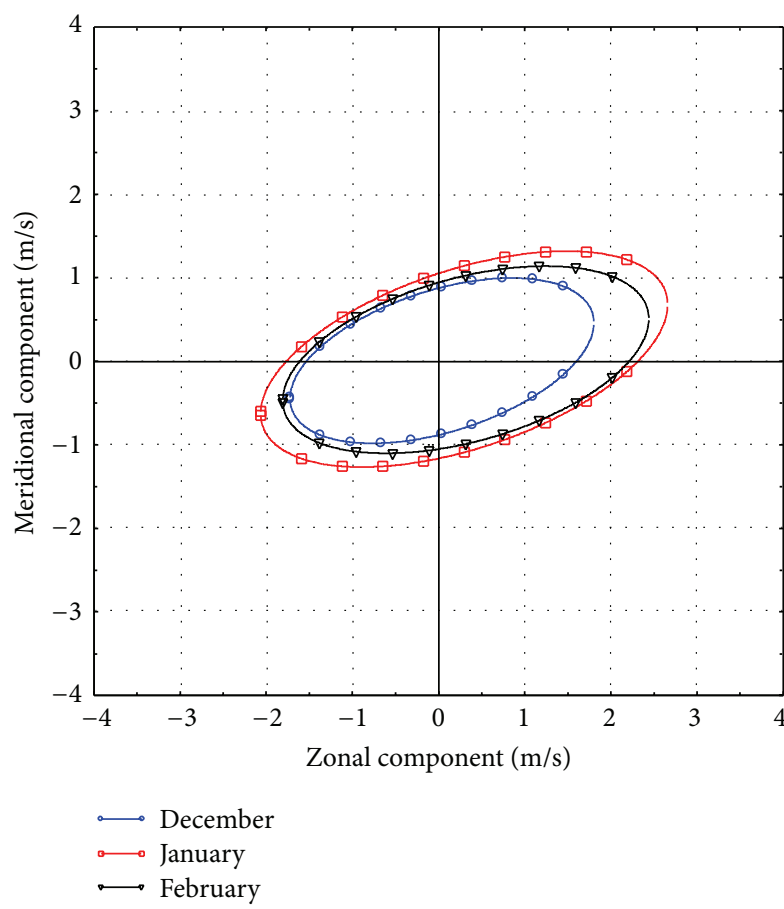

(a)

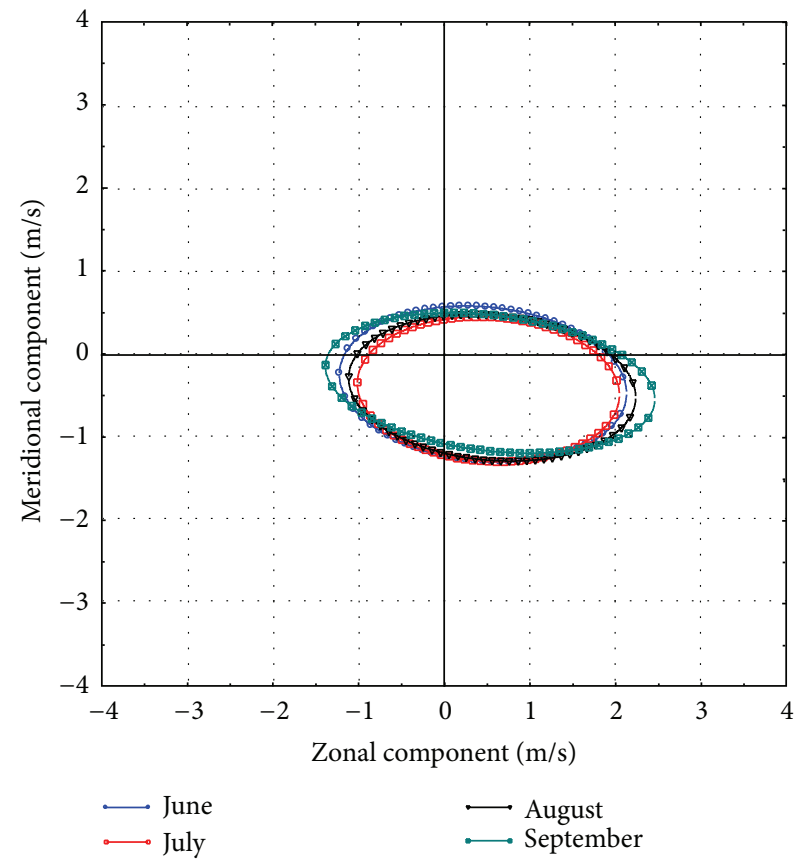

(b)

FIGURE 25: Bivariate normal distribution ellipses for (a) winter and for (b) SW monsoon months.

values are due to bushy and cashew vegetations between NNW and NE sector.

$z_{0}$ variations during different strengths of the SW monsoon activity over the region are studied. The strength of SW monsoon is called weak when the rainfall is less than half of the normal and vigorous if the monsoon rainfall is more than 4 times the normal under the conditions that the rainfall in at least two stations should be $8 \mathrm{~cm}$ (if the subdivision is along the west coast of India) and rainfall in the meteorological subdivision should be fairly widespread or widespread. The data on daily strength of SW monsoon and rainfall used in this study are made available from the daily weather report from Meteorological Centre, IMD, Thiruvananthapuram, Kerala. Figure 28 shows average $z_{0}$ values obtained during 10 weak and vigorous days from 2007 to 2012. Numbers $(N)$ of $z_{0}$ observations are 2424 and 2404 for weak and vigorous monsoon, respectively. Average values of weak and vigorous monsoons are $0.056 \mathrm{~m}$ and $0.098 \mathrm{~m}$, respectively, attributed to more northerliness of synoptic wind flow towards $325^{\circ}$ coast azimuth. 


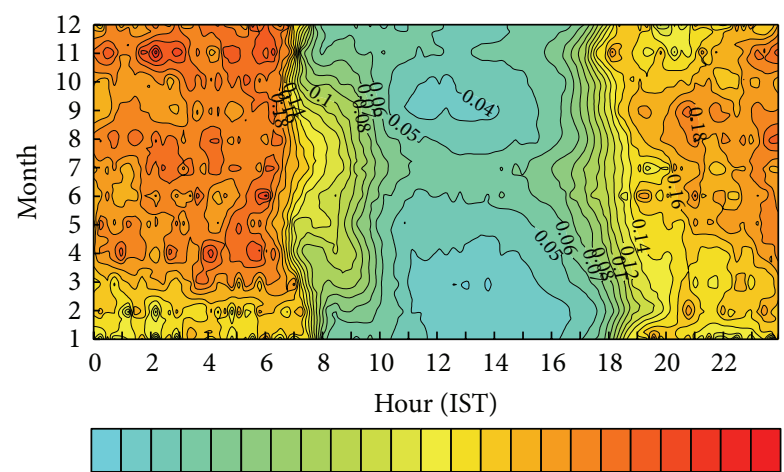

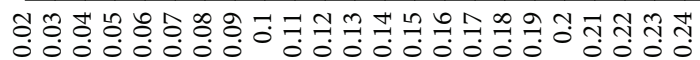

(m)

FIGURE 26: Mean monthly structure of roughness parameter $\left(z_{0}\right)$ for unstable cases $(z / L<0)$.

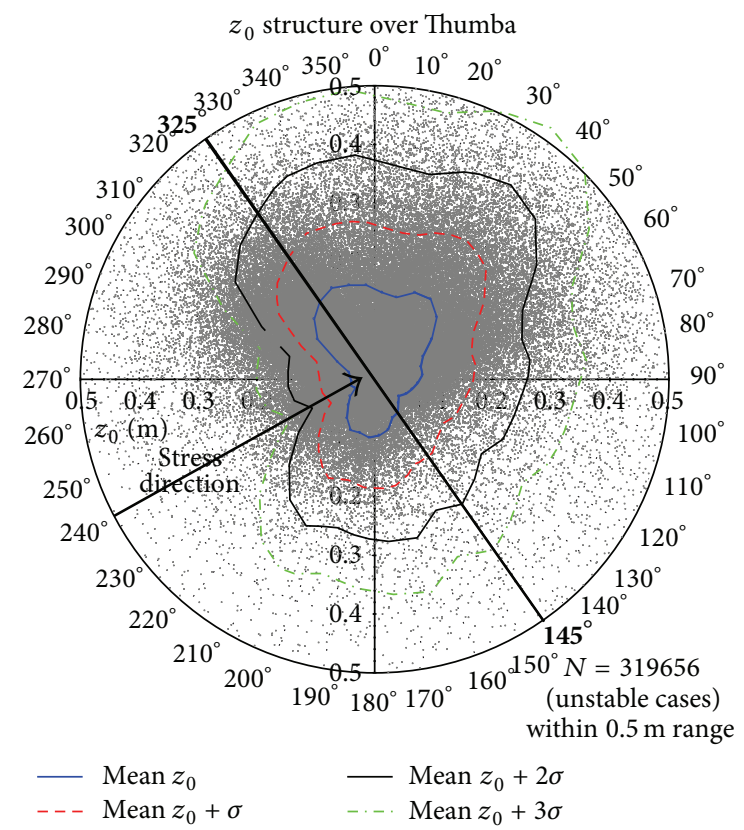

FIGURE 27: Polar plot of $z_{0}$ with respect to wind direction.

\section{Conclusions}

Detailed characterizations of lower SBL features and corresponding physical/meteorological mechanisms pertained are investigated and discussed over TERLS for potential applications and characterization of tropical SBL. The following are the salient results.

(i) $u_{*}$ peaks at $1 / L \rightarrow 0$ and small $u_{*}$ values associated with high - ve $1 / L$ values are due to heat convection and those with +ve $1 / L$ values are due to severely reduced mechanical turbulence. Medium values of $u_{*}$ are due to mechanical turbulence caused by temperature stratification and inertia. Peak $u_{*}$ during $1 / L \rightarrow$ 0 is in the neutral regime.

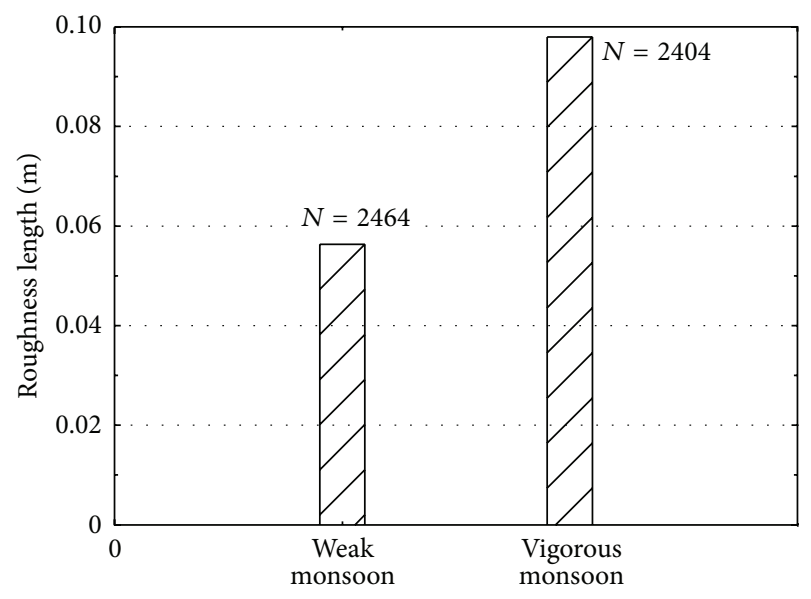

FIGURE 28: Average values of $z_{0}$ during 10 cases of weak and vigorous monsoon days from 2007 to 2012.

(ii) $\sigma_{w}$ Vs $u_{*}$ distribution has shown typical neutral $u_{*}$ value.

(iii) Power curves relations of the form $\sigma / u_{*}=a+$ $b(z / L)^{c}$ are fitted among normalized variances of $(p, q, r, T)$ and $z / L$. In the weakly unstable or stable regime of $z / L$ from -10 to 10 with maximum $z / L$ points of occurrences, $z / L$ and variances are in poor dependence with constancy in variances. Beyond $z / L$ $= \pm 10$, variances enhance abruptly in the region of high stable or unstable regime. Neutral regime has been identified between $z / L$ from -0.03 to 0.02 .

(iv) Scatter of points for different wind directions against $z / L$ shows that onshore SBL wind profiles are of mostly unstable nature, whereas offshore wind profiles belong to either stable or unstable type.

(v) Significant decrease/increase in wind speed in stress off-wind angle $(\alpha)$ is seen with respect to wind speed increase/decrease.

(vi) The structure of MRWD has shown wind direction climatology. Due to the dominant synoptic-scale SW monsoon system influence, sea-breeze flow has been seen throughout the day.

(vii) In the mutual orientation of wind and stress vectors coterminus/collinear orientation corresponds to +ve/-ve $M$ values, respectively.

(viii) The net effect of both updrafts and downdrafts in the SBL is always to maintain a net flux of momentum downwards and results in negative values.

(ix) The most dominant mean direction of the stress for this station is from about $242^{\circ}$ during day time portion of the SW monsoon season.

(x) The highest scalar speeds in the diurnal course correspond to the highest negativity in momentum flux values. 
(xi) Large $u_{*}$ values during sea breeze compared to land breeze indirectly explain that wind shear generated by sea breeze is higher than that produced by land breeze.

(xii) The portions of the greatest -ve $w$ components are associated with the greatest values in the net downward momentum flux.

(xiii) From 0730 IST to $1800 / 1900$ IST it is observed that the $L$ values are negative, and in the rest of the periods the values are positive. Strong/light negative $L$ values are the characteristics of highly/weakly unstable conditions and strong/light positive $L$ values designate highly/weakly stable conditions.

(xiv) The occurrence of neutral regimes is mostly during evening, night, and early hours of the day till about 0900 IST in SW monsoon.

(xv) The highest values in turbulent heat flux encountered during winter are of the order of above $280 \mathrm{~W} \mathrm{~m}^{-2}$.

(xvi) The lowest $C_{D}$ values of less than 0.04 are observed during the sea-breeze regime between 1300 IST and 1600 IST. Changes in $C_{D}$ with the wind speed are rapid compared to $u_{*}$.

(xvii) Variations in turbulent intensities show similar features, which can be interpreted that an eddy which influences the measuring level will have equal contribution among the three perpendicular wind components.

(xviii) In the SW monsoon featured by strong updraft currents (and thereby strong convection) greater values in both TKE per eddy size and eddy sizes are seen, whereas during air subsidence predominant winter month, January has contributed to lesser extent to TKE and in eddy size.

(xix) Abrupt increase of TKE and thereby eddy size has been observed with changeover of land breeze to sea breeze and during the passage of a thunderstorm.

(xx) Inverse proportionality is detected between $\sigma_{\theta}$ and WSF. Whenever the mesoscale onshore/offshore flow is opposite to the synoptic scale seasonal flow direction, the resultant $\sigma_{\theta}$ are higher unlike low values for same direction interactions. During thunderstorm event, $\sigma_{\theta}$ increase and WSF decrease are observed.

(xxi) BND ellipse orientation is based on the prevailing wind direction of the season and larger measure of major axes in ellipses shows the dominance of zonal components.

(xxii) Mean structure of $z_{0}$ ranges from $0.02 \mathrm{~m}$ to $0.24 \mathrm{~m}$ with respect to wind direction and most of the $z_{0}$ values are within $0.5 \mathrm{~m}$. Low and high $z_{0}$ values are clearly observed during onshore and offshore flows, respectively, with sharp decrease around $242^{\circ}$ due to orientation of the wind stress vector along this particular direction $\left(242^{\circ}\right)$. Build-up in $z_{0}$ starts as nearing to the coast at $325^{\circ}$ orientation due to land frictional effect and maxima in $z_{0}$ happen around $35^{\circ}$ azimuth. (xxiii) Average $z_{0}$ values of weak and vigorous monsoons are $0.056 \mathrm{~m}$ and $0.098 \mathrm{~m}$, respectively.

\section{Conflict of Interests}

The authors declare that there is no conflict of interests regarding the publication of this paper.

\section{References}

[1] J. C. Wyngaard, "On surface-layer turbulence," in Workshop on Micrometeorology, D. A. Haugen, Ed., pp. 101-149, American Meteorological Society, Boston, Mass, USA, 1973.

[2] G. A. McBean, Ed., Planetary Boundary Layer: Technical Note No. 165, World Meterological Organization, Geneva, Switzerland, 1979.

[3] H. A. Panofsky and J. A. Dutton, Atmospheric Turbulence, Academic Press, New York, NY, USA, 1984.

[4] R. E. Huschke, Ed., Glossary of Meteorology, American Meteorological Society, Boston, Mass, USA, 1959.

[5] J. A. Businger, "Turbulence transport in the atmospheric surface layer," in Workshop on Micrometeorology, D. A. Haugen, Ed., pp. 67-100, American Meteorological Society, Boston, Mass, USA, 1973.

[6] A. S. Monin and A. M. Obukhov, "The basic laws of turbulent mixing in the surface layer of the atmosphere," Trudy Botanicheskogo Instituta Akademii Nauk SSSR, vol. 24, no. 151, pp. 163187, 1954.

[7] C. A. Paulson, "The mathematical representation of wind speed and temperature profiles in the unstable atmospheric surface layer," Journal of Applied Meteorology, vol. 9, no. 6, pp. 857-861, 1970.

[8] K. G. Rao, S. Raman, A. Prabhu, and R. Narasimha, "Turbulent heat flux variation over the Monsoon-Trough region during MONTBLEX-90," Atmospheric Environment, vol. 29, no. 16, pp. 2113-2129, 1995.

[9] C. J. Nappo, "Mesoscale flow over complex terrain during the Eastern Tennessee Trajectory Experiment (ETTEX)," Journal of Applied Meteorology, vol. 16, no. 11, pp. 1186-1196, 1966.

[10] A.-S. Smedman-Hogstrom and U. Hogstrom, "A practical method for determining wind frequency distributions for the lowest $200 \mathrm{~m}$ from routine meteorological data," Journal of Applied Meteorology, vol. 17, no. 7, pp. 942-954, 1978.

[11] B. B. Hicks, P. Hyson, and C. J. Moore, "A study of eddy fluxes over a forest," Journal of Applied Meteorology, vol. 4, pp. 58-66, 1975.

[12] J. Kondo and H. Yamazawa, "Aerodynamic roughness over an inhomogeneous ground surface," Boundary-Layer Meteorology, vol. 35, no. 4, pp. 331-348, 1986.

[13] R. S. Thompson, "Notes on the aerodynamic roughness length for complex terrain," Journal of Applied Meteorology, vol. 17, no. 9, pp. 1402-1403, 1978.

[14] J. R. Garratt, "Review of drag coefficients over oceans and continents," Monthly Weather Review, vol. 105, pp. 915-929, 1977.

[15] H. A. Panofsky and E. L. Peterson, "Wind profiles and change of surface roughness at Riso," Quarterly Journal of the Royal Meteorological Society, vol. 98, pp. 845-854, 1972.

[16] J. C. Kaimal, R. A. Eversole, D. H. Lenschow, B. B. Stankov, P. H. Kahn, and J. A. Businger, "Spectral characteristics of the convective boundary layer over uneven terrain," Journal of the Atmospheric Sciences, vol. 38, no. 5, pp. 1098-1114, 1982. 
[17] A. Korrell, H. A. Panosky, and R. J. Rossi, "Wind profiles at the Boulder Tower," Boundary-Layer Meteorology, vol. 22, no. 3, pp. 295-312, 1982.

[18] R. Ramachandran, J. W. J. Prakash, K. S. Gupta, K. N. Nair, and P. K. Kunhikrishnan, "Variability of surface roughness and turbulence intensities at a coastal site in India," Boundary-Layer Meteorology, vol. 70, no. 4, pp. 385-400, 1994.

[19] S. K. Gupta, P. K. Kunhikrishnan, R. Ramachandran, J. W. J. Prakash, and K. N. Nair, "On the characteristic of coastal atmospheric boundary layer," Global Change Studies, Indian Space Research Organisation Scientific Report no. ISRO-GBPSR-42-94, 1994.

[20] K. V. S. Namboodiri, Studies on the vertical structure of horizontal wind variability in the surface boundary layer over Sriharikota [Ph.D. thesis], Cochin University of Science and Technology, Cochin, India, 2000.

[21] H. A. Panofsky, H. Tennekes, D. H. Lenschow, and J. C. Wyngaard, "The characteristics of turbulent velocity components in the surface layer under convective conditions," Boundary-Layer Meteorology, vol. 11, no. 3, pp. 355-361, 1977.

[22] P. Krishnan and P. K. Kunhikrishnan, "Some characteristics of atmospheric surface layer over a tropical inland region during southwest monsoon period," Atmospheric Research, vol. 62, no. 1-2, pp. 111-124, 2002.

[23] K. N. Nair, P. K. Kunhikrishnan, R. Ramachandran, K. S. Gupta, and J. W. J. Prakash, "Surface layer studies using tower based measurements at Thumba, India," in Proceedings of the 5th International Symposium on Acoustic Remote Sensing of the Atmosphere and Oceans, pp. 325-329, Tata McGraw-Hill, New Delhi, India, 1990.

[24] M. V. Ramana, P. Krishnan, and P. K. Kunhikrishnan, "Surface Boundary-Layer characteristics over a tropical inland station: seasonal features," Boundary-Layer Meteorology, vol. 111, no. 1, pp. 153-175, 2004.

[25] M. Pahlow, M. B. Parlange, and F. Porte-Agel, "On MoninObukhov similarity in the stable atmospheric boundary layer," Boundary-Layer Meteorology, vol. 99, no. 2, pp. 225-248, 2001.

[26] G. L. Geernaert, F. Hansen, M. Courtney, and T. Herbers, "Directional attributes of the ocean surface wind stress vector," Journal of Geophysical Research, vol. 98, no. 9, pp. 16571-16582, 1993.

[27] A. A. Grachev and C. W. Fairall, "Upward momentum transfer in the marine boundary layer," Journal of Physical Oceanography, vol. 31, no. 7, pp. 1698-1711, 2001.

[28] B. Lange, S. Larsen, J. Hojstrup, and R. Barthelmie, "The influence of thermal effects on the wind speed profile of the coastal marine boundary layer," Boundary-Layer Meteorology, vol. 112, no. 3, pp. 587-617, 2004.

[29] T. Kilpelainen and A. Sjoblom, "Momentum and sensible heat exchange in ice-free Arctic Fjord," Boundary-Layer Meteorology, vol. 134, no. 1, pp. 109-130, 2010.

[30] W. Brutsaert, "Aspects of bulk atmospheric boundary layer similarity under free-convective conditions," Reviews of Geophysics, vol. 37, no. 4, pp. 439-451, 1999.

[31] H. C. Friebel, A. Y. Benilov, J. L. Hanson, and D. T. Resio, "Long-term drag coefficient measurements in the coastal zone," USACE-FRP Report, US Army Corps of Engineers-NAP, 2009.

[32] P. K. Kunhikrishnan, Studies of atmospheric boundary layer [Ph.D. thesis], Kerala University, Kerala, India, 1990.

[33] J. C. Kaimal and J. J. Finnigan, Atmospheric Boundary Layer Flows, There Structure and Measurement, Oxford University Press, New York, NY, USA, 1994.
[34] W. J. Prakash, R. Ramachandran, K. N. Nair, K. S. Gupta, and P. K. Kunhikrishnan, "On the spectral behaviour of atmospheric boundary-layer parameters at Thumba, India," Quarterly Journal of the Royal Meteorological Society, vol. 119, no. 509, pp. 187197, 1993.

[35] C. Biltoft, "Momentum flux: gross, scalar, along wind or net?" Adiabat Meteorological Services Note 0303, Applied Technologies, 2003.

[36] K. V. S. Namboodiri, P. K. Dileep, K. Mammen et al., "Effects of annular solar eclipse of 15 January 2010 on meteorological parameters in the 0 to $65 \mathrm{~km}$ region over Thumba, India," Meteorologische Zeitschrift, vol. 20, no. 6, pp. 635-647, 2011.

[37] A. S. Monin and A. M. Yaglom, Statistical Fluid Mechanics: Mechanics of Turbulence, vol. 1, The MIT Press, Cambridge, Mass, USA, 1971.

[38] J. C. Wyngaard and O. R. Cote, "Cospectral similarity in the atmospheric surface layer," Quarterly Journal of the Royal Meteorological Society, vol. 98, no. 417, pp. 590-603, 1972.

[39] A. Smedman, "Observations of a multi-level turbulence structure in a very stable atmospheric boundary layer," BoundaryLayer Meteorology, vol. 44, no. 3, pp. 231-253, 1988.

[40] L. Mahrt, "Stratified atmospheric boundary layers and breakdown of models," Theoretical and Computational Fluid Dynamics, vol. 11, no. 3-4, pp. 263-279, 1998.

[41] K. F. Rieder, J. A. Smith, and R. A. Weller, "Observed directional characteristics of the wind, wind stress, and surface waves on the open ocean," Journal of Geophysical Research, vol. 99, no. 11, pp. 22589-22596, 1994.

[42] G. L. Geernaert, "Measurements of the angle between the wind vector and wind stress vector in the surface layer over the North Sea," Journal of Geophysical Research: Oceans, vol. 93, no. 7, pp. 8215-8220, 1988.

[43] P. O. G. Persson, B. Walter, and J. Hare, "Maritime differences between wind direction and stress: relationships to atmospheric fronts and implications," in Proceedings of the 13th Conference on Interactions of the Sea and Atmosphere, Portland, Me, USA, August 2004.

[44] T. R. Oke, Boundary Layer Climates, Halsted Press, New York, NY, USA, 1978.

[45] G. E. Willis and J. W. Deardorff, "On the use of Taylor's translation hypothesis diffusion in the mixed layer," Quarterly Journal of the Royal Meteorological Society, vol. 102, no. 434, pp. 817-822, 1976.

[46] R. B. Stull, An Introduction to Boundary Layer Meteorology, Kluwer Academic Publishers, Dordrecht, The Netherlands, 1994.

[47] G. R. Ackermann, "Means and standard deviations of horizontal wind components," Journal of Climate and Applied Meteorology, vol. 22, no. 5, pp. 959-961, 1983.

[48] K. A. Verrall and R. L. Williams, "A method of estimating the standard deviation of wind directions," Journal of Applied Meteorology, vol. 21, no. 12, pp. 1922-1925, 1982.

[49] R. J. Yamartino, "A comparison of several "single-pass" estimators of the standard deviation of wind direction," Journal of Climate and Applied Meteorology, vol. 23, no. 9, pp. 1362-1366, 1984.

[50] D. B. Turner, "Comparison of three methods for calculating the standard deviation of the wind direction," Journal of Climate and Applied Meteorology, vol. 25, no. 5, pp. 703-707, 1986.

[51] K. V. S. Namboodiri, P. K. Dileep, and K. Mammen, "Wind steadiness up to $35 \mathrm{~km}$ and its variability before the southwest 
monsoon onset and the withdrawal," Mausam, vol. 63, no. 2, pp. 275-282, 2012.

[52] K. V. S. Namboodiri, G. V. Rama, and K. Mohan Kumar, "Distribution of horizontal wind components in the Surface Boundary Layer (SBL) over Sriharikota," Mausam, vol. 57, no. 2, pp. 301-306, 2006. 

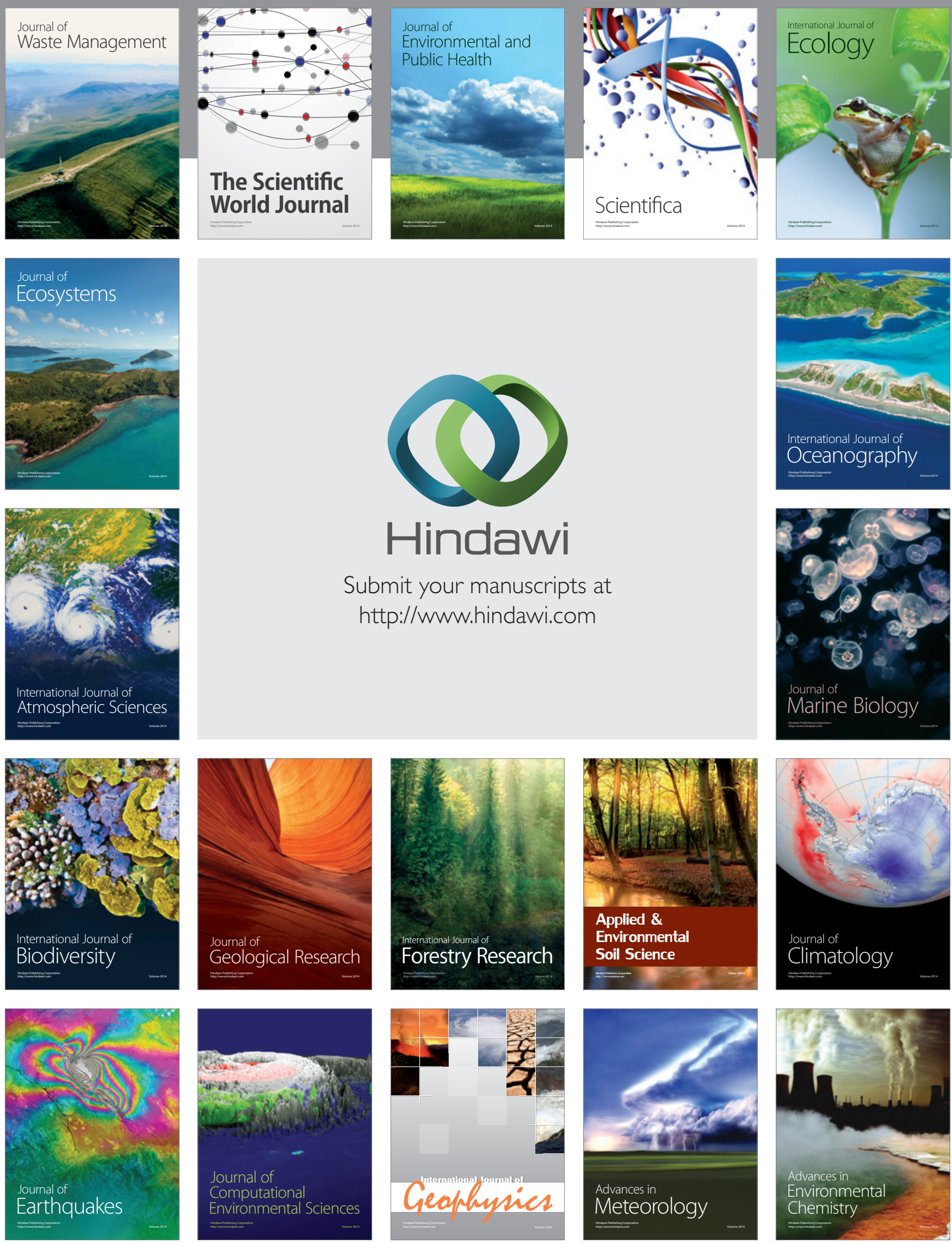